Revista de Ciencias Sociales - Número 70 (2017) - Páginas 123-168

Elementos para un análisis de la relación entre el derecho fundamental...

\title{
ELEMENTOS PARA UN ANÁLISIS DE LA RELACIÓN ENTRE EL DERECHO FUNDAMENTAL A HUELGA Y LA VIOLENCIA
}

\author{
INITIAL ELEMENTS FOR AN ANALYSIS OF THE \\ RELATIONSHIP BETWEEN THE FUNDAMENTAL \\ RIGHT TO STRIKE AND VIOLENCE IN CHILE
}

\author{
FRANCISCO ALBERTO RUAY SÁEZ* \\ Universidad de Chile \\ fruay@ug.uchile.cl
}

\section{Resumen}

En la presente investigación se pretende delinear un estudio posible de la relación teórica entre derecho a huelga, como derecho fundamental, y la violencia. El estudio se compone esencialmente de tres cuerpos analíticos entrelazados; el primero versa sobre la exposición de la huelga como fenómeno de tránsito histórico, en su vinculación con el movimiento obrero; en un segundo momento, se desarrolla brevemente el tránsito hacia su consagración jurídica; para dejar, por último, un espacio de exposición a la relación entre violencia y derecho a huelga, valiéndonos en tal desarrollo fundamentalmente en los planteamientos desarrollados por Walter Benjamin.

* Abogado. Licenciado en Ciencias Jurídicas y Sociales, Universidad de Chile. Ayudante ad honorem de los departamentos de Derecho del Trabajo y de la Seguridad Social, y de Ciencias Penales en la Universidad de Chile. Artículo recibido el 24 de abril de 2017 y aceptado el 9 de junio de 2017.

Revista de Ciencias Sociales - Número 70 (2017) - Universidad de Valparáíso - ISSN 0716-7725-Valparaíso, Chile 
Francisco Alberto Ruay Sáez

\title{
Palabras clave
}

Huelga-Violencia-Estado de Derecho-derechos fundamentales.

\begin{abstract}
The study is essentially composed of three interlocking analytical sections; the first concerns the exposure of the strike as a phenomenon of historical transition in its relationship with the labor movement; in a second moment, briefly it develops the transition to its legal consecration; to leave, finally, an exhibition space to the relationship between violence and the right to strike, availing ourselves in this development mainly in the approaches developed by Walter Benjamin.
\end{abstract}

\section{Keywords}

Right to Strike-Violence-Rule of Law-fundamental rights.

\section{INTRODUCCIÓN}

No son muchas las intervenciones en las cuales se abre la posibilidad de desarrollar una discusión sobre lo propiamente jurídico del Derecho (y "los derechos") orientando la lectura de dicho fenómeno hacia sus propias cimientes, sin que esto implique necesariamente omitir los textos normativos positivos y los avances de la dogmática jurídica, lo que en la mayoría de las ocasiones nos arroja a un análisis de teoría del derecho o filosofía del Derecho ${ }^{1}$, pero que termina en todo caso atravesando por igual a la teoría del Derecho, la filosofía del Derecho y la doctrina jurídica ${ }^{2}$. Tal vez dicha distinción, al igual que todas las posibilidades radicales de la diferencia ${ }^{3}$, no es del todo clara, e incluso,

1. VERGARA, Blanco, Alejandro: "Delimitar y distinguir: teoría del derecho, filosofía del derecho y doctrina jurídica”. En: Revista de derecho (Valparaíso), $\mathrm{N}^{\mathrm{a}}$ 44, 623-660, 2015. Pág. 627.

2. MILLAS, Jorge: Filosofía del derecho. Comentarios, notas y edición de Juan O. Cofré. Santiago de Chile: Ediciones Universidad Diego Portales, 2012. Págs. 99-100.

3. DERRIDA, Jaques: La diferencia. Edición electrónica de www.philosophia.cl / Escuela de Filosofía Universidad ARCIS. Recuperado de: http://www. uruguaypiensa.org.uy/imgnoticias/590.pdf 1968

Facultad de Derecho y Ciencias Sociales - Universidad de Valparaíso - Chile

124 
es meramente aparente, o al menos, no se nos presenta allí donde creemos observarla.

Una vez iniciados en la práctica cotidiana del derecho, la de los operadores jurídicos directos, ésta modela una forma de represión (como mecanismo de defensa) representada en la negación ${ }^{4-5}$ ante aquello innombrable que se encuentra en la cimiente misma de lo jurídico: la violencia. Olvidada ésta en el marco de un sistema jurídico vigente, y enclaustrada en su versión legítima simplemente en la "coerción" parece que el único lugar que le cabe es el de "fuera" de la legalidad, el del Otro que no es Derecho, por definición. Aquél lugar en donde reina el salvajismo, el estado de naturaleza ${ }^{6}$ y la posibilidad de la desaparición y muerte del sujeto, que por cierto, en ésta lógica, no puede sino ser sujeto de derecho. El Derecho como estado de paz y orden, como pacificación social y ordenamiento de las voluntades individuales libres ${ }^{7}$, que cabrá añadir, "racionales" libres.

Pero incluso en el escenario antedicho la violencia tiene un diálogo interno con el Derecho, al menos en dos momentos. En uno primero, y es obvio, bajo el prisma anteriormente expuesto, violencia como indicio del lugar de lo antijurídico, como una señal de presencia del extranjero enemigo como fuera del Derecho ${ }^{8}$ o como enemigo interno del no-persona ${ }^{9}$. En ese sentido, la violencia se manifiesta en

4. KENNEDY, Duncan: Izquierda y derecho. Ensayos de teoría jurídica crítica. Buenos Aires: Editorial Siglo XXI, 2010. Pág. 54.

5. Lo mismo ocurre con la idea de que es posible interpretar y aplicar el derecho desprovisto de ideología.

6. HOBBES, Thomas: Leviatán, o La materia, forma y poder de una república eclesiástica y civil. Madrid: Editorial Sarpe, 1984. Pág. 139.

7. KANT, Immanuel: Principios metafísicos del Derecho, Madrid: Librería de Victoriano Suárez, 1873. Trad. de Gonzalo Lizárraga. Pág. 43.

8. ROUSSEAU, Jean Jacques: El contrato social. Santiago de Chile: Ediciones Centro gráfico, 2005. Pág. 34.

9. JAKOBS, Günther y CANCIO MELIÁ, Manuel: Derecho penal del enemigo. Madrid: Civitas, 2003. Pág. 28.

Revista de Ciencias Sociales - Número 70 (2017) - Universidad de Valparáíso - ISSN 0716-7725-Valparaíso, Chile 
aquellos lugares en que un sujeto (de derecho) actúa en contravención a lo dispuesto por la ley, o más propiamente dicho, desplegando un acto antijurídico ${ }^{10}$, sea porque con el acto se vulneran los derechos de otro sujeto $^{11}$, sea porque derechamente se opone al Derecho mismo ${ }^{12}$. La denominación de "acto ilícito" o "acto antijurídico" a aquellos que se oponen al Ordenamiento Jurídico contienen su identificación significante en la posibilidad de identificación de un "bien jurídico" que se estima como lesionado o vulnerado. El Derecho Penal, y la noción de que los "bienes jurídicos" (una visión crítica en Roxin) ${ }^{13}$ de mayor trascendencia son objeto de su protección constituyen el ejemplo paradigmático de la circunstancia antedicha. Es precisamente en el Derecho Penal en donde se manifiesta de manera más evidente el discurso jurídico que pretende reconocer lo violento como un lugar fuera de sí, como violencia pura o coacción y no como coerción.

Sin embargo, el Derecho dentro de sí da cabida excepcionalmente a la violencia, mediada por su autorización/legitimación como coerción ${ }^{14}$ en su faz sancionadora. El uso de la violencia legítima de parte de los particulares es vista como una amenaza ${ }^{15}$ y debe ser excepcional, pues de lo contrario no sólo sería una ley la que se pone en riesgo, ni una Constitución, como norma suprema de determinado sistema jurídico,

10. MILLAS, Jorge: ob. cit., p. 302; KELSEN, Hans. Teoría pura del derecho, México: Porrúa, 1998. Pág. 123.

11. KANT, Immanuel: op. cit., p. 43.

12. SQUELLA NARDUCCI, Agustín: Introducción al Derecho, Santiago de Chile: Editorial Jurídica de Chile, 2000. Págs. 531 y ss.

13. ROXIN, Claus: El concepto de bien jurídico como instrumento de crítica legislativa sometido a examen. En: Revista electrónica de ciencia penal y criminología, $\mathrm{N}^{\circ}$ 15, 2013, Rescatado de: http://criminet.ugr.es/recpc/15/recpc15-01.pdf Pág. 5.

14. NINO, Carlos Santiago: Introducción al análisis del derecho, Barcelona: Ariel, 1997. Pág. 168.

15. BENJAMIN, Walter: Para una crítica de la violencia y otros ensayos, Iluminaciones IV, Madrid: Taurus, 1991. Traducción de Roberto Blatt. Pág. 26.

Facultad de Derecho y Ciencias Sociales - Universidad de Valparaíso - Chile 
sino que sería el propio Derecho quien se abre a la posibilidad de no ser tal; de no conservarse. El Estado de Derecho radica en sí el monopolio de la violencia, y la autotutela ${ }^{16}$ queda reducida a un espacio marginal, a una posibilidad excepcional en donde sólo bajo circunstancias calificadas un sujeto particular se encuentra legitimado para actuar violentamente. En éste caso, la posibilidad de dicha actuación no implica el ejercicio de un derecho, obviamente, de lo contrario se encontraría cubierto por el ordenamiento jurídico de manera positiva, aunque puede relacionarse la tolerancia excepcional de la violencia, eso sí, con la protección de un bien jurídico.

Tal vez mayor atracción representa la vinculación Derecho y violencia en aquellos casos en que pareciese que se ejerce una "violencia legítima”, o violencia jurídica, en virtud de la actuación o ejercicio de un derecho subjetivo. En otras palabras, en aquellos casos en que esa distinción o relación de exterioridad entre violencia y Derecho parece diluirse, o a lo menos ser lo suficientemente turbia para no permitir establecer con claridad sus deslindes. Cuando la actuación de un derecho, legítimo, mediado por el Estado requiere o se despliega como ejercicio coercitivo del poder estatal; como mediación de exigibilidad coercitiva. Es precisamente en éste lugar en donde encontramos a la huelga, ya no como un hecho o fenómeno social, respecto del cual en un tiempo futuro el Derecho habrá de hacerse cargo, sino que como la realidad efectiva de que el ordenamiento jurídico lo ha consagrado como un derecho, y contemporáneamente, casi sin mayor discusión, como un derecho fundamental ${ }^{17}$.

Para aproximarnos al análisis de la huelga nos adentraremos en primer lugar en lo que la doctrina jurídica laboralista nacional ha determinado como su trayecto histórico, concepto, alcance y configuración iusfundamental. Luego, en un segundo apartado desarrollaremos una aproximación a la relación entre huelga y violencia, diferenciando

16. COLOMBO CAMPBELL, Juan: La Jurisdicción en el Derecho Chileno. Santiago de Chile: Editorial Jurídica de Chile, 1991. Pág. 11.

17. VERDUGO, Mario; PFEFFER, Emilio y NOGUEIRA, Humberto: Derecho Constitucional. Tomo I, Santiago de Chile: Editorial Jurídica de Chile, 2a ed., 1999. Pág. 292.

Revista de Ciencias Sociales - Número 70 (2017) - Universidad de Valparáíso - ISSN 0716-7725-Valparaíso, Chile 
distintas presentaciones de la misma y una posibilidad de análisis dialéctico desde el pensamiento de Walter Benjamin.

\section{LA HUELGA: TRÁNSITO A SU CODIFICACIÓN Y SU CONSAGRACIÓN COMO DERECHO FUNDAMENTAL}

\section{Breve exposición de la huelga previo a su regulación legal}

Si bien no es la finalidad de esta presentación el otorgar una exposición completa y detallada de los avatares que transcurren en el vaivén histórico de la huelga, y con ello, de los trabajadores y los movimientos que le han congregado, es pertinente al menos hacer alusión al fenómeno histórico que puede considerarse no sólo como antecedente del derecho fundamental a huelga, sino que del Derecho del Trabajo mismo.

La relación de trabajo encuentra en su cimiente constitutiva una relación antagónica que reúne los intereses del empleador, tradicionalmente identificado como "propietario" de los medios de producción (de trabajo) ${ }^{18}$, por un lado, y el oferente de su fuerza de trabajo por otro (el trabajador). El elemento central y definitorio de dicha relación jurídica es la subordinación y dependencia, ambos elementos tipificados legalmente y desarrollados y configurados por la doctrina y jurisprudencia a partir de la interpretación de la ley ${ }^{19}$. Es precisamente dicha circunstancia la que permitiría diferenciar esta relación jurídica particular de otra cualquiera, y en particular, de aquellas de naturaleza civil. Pero hasta aquí no hemos hecho más que reproducir sintéticamente lo que tantas veces se ha reiterado por la doctrina iuslaboralista; sin embargo, debemos dar un paso hacia la lectura de la condición de posibilidad de su enunciación como derecho autónomo; como Derecho

18. HARNECKER, Marta: Los conceptos elementales del materialismo histórico, Madrid: Siglo XXI, $24^{\circ}$ edición, 1974. Pág. 22.

19. UGARTE CATALDO, José Luis. "La subordinación jurídica y los desafíos del nuevo mundo del trabajo". En: Gaceta Laboral, N 11 (1), 2005. Págs. 23-50.

Facultad de Derecho y Ciencias Sociales - Universidad de Valparaíso - Chile 
del trabajo o Derecho laboral, y para ello debemos visitar un hecho anterior al propio lenguaje de los derechos ${ }^{20}$.

Previo a la codificación del derecho del trabajo, y a su fundación como disciplina con autonomía relativa, el lenguaje de los derechos se encontraba limitado a enunciar a los trabajadores netamente como sujetos individuales de derecho, por supuesto libres, que en el ejercicio de la autonomía de su voluntad se vinculaban con otro sujeto, igualmente libre, para con quien se obligaban a prestar servicios a cambio del pago de un precio.

Sin perjuicio de lo anterior, con el desarrollo de la revolución industrial, paralelo a la expansión del desarrollo productivo impulsado por el capitalismo, la subjetividad laboral en el discurso político y económico de los propios trabajadores trascendía aquella limitación individualista de raíz liberal y heredera de la tradición ilustrada que con la revolución francesa, y la codificación napoleónica, había abstraído los sujetos, y sus subjetividades, para predicarlos como sujetos de derechos, como titulares de derechos. Las condiciones de vida de los trabajadores, y la influencia ideológica ${ }^{21}$ de los pensadores de izquierda, revolucionaria o reformista conservadora, o socialdemócrata, propiciaron que el discurso de los obreros que hablaban de "clase trabajadora", "proletarios" o "compañeros", volcara a la práctica efectiva sus posibilidades de petición, o imposición, como una expresión de fuerza. La huelga se presenta eminentemente como un medio para la obtención de peticiones colectivas, compartidas por una clase que compartía no sólo mismas formas de vida, sino que incluso jornadas, condiciones de salud, los espacios físicos, entre tantas otras ${ }^{22}$. La huelga

20. GLENDON, Mary Ann: "El lenguaje de los derechos". En: Estudios Públicos, No 70, Santiago de Chile, 1998, p. 78; y, CRUZ PARCERO, Juan Antonio: El lenguaje de los derechos. Ensayo para una teoría estructural de los derechos, Trotta, 2007. Págs. 22 y ss.

21. DEVÉS, Eduardo y DÍAZ, Carlos: El pensamiento socialista en Chile (Antología 1893-1933). Ediciones Documentas, Santiago de Chile, 1987. Págs. 13 y ss.

22. SALAZAR, Gabriel: Labradores, peones y proletarios (Siglo XIX), Santiago de Chile: Ediciones SUR, 1989. Págs. 219.

Revista de Ciencias Sociales - Número 70 (2017) - Universidad de Valparáíso - ISSN 0716-7725-Valparaíso, Chile 
se presenta como un hecho eminentemente político-económico, que funda su discurso no en el lenguaje de los derechos institucionalizados de aquel entonces, y sus esferas de legitimidad, sino que como una fuerza exterior al propio Derecho ${ }^{23}$, que (ad) viene a forzarlo, para algunos, a transformarlo, para otros, o incluso hasta a destruirlo y destronarlo como forma idónea de organización social, en el caso de las posiciones obreras más radicales ${ }^{24}$.

Si al referirse a la huelga se hacía alguna mención a un derecho, éste uso no era técnicamente jurídico o, al menos, podemos afirmar que no era un uso referido a la legitimidad del derecho como derecho positivo conforme al ordenamiento jurídico vigente (podría pensarse algo contrario si se pretende adoptar una teoría iusnaturalista del derecho $\left.{ }^{25}\right)$. Lo mismo en el caso de la violencia; ningún sujeto particular en aquel entonces (y menos ahora) puede afirmar coherentemente que es titular de un "derecho a la violencia”, en el sentido en que el lenguaje del derecho entiende dicha expresión.

Esencialmente, previo a la consagración de la huelga como derecho, o como un hecho de relevancia jurídica que requería ser regulado desde y en el Derecho, ésta se situaba como absolutamente Otro del mismo, pero particularmente, como un Otro enemigo. Este relato es coincidente con la tradicional figura epocal que divide en tres etapas o estadios la relación de la huelga con el Derecho; un primer estadio en donde se ubicaba sólo al lado de la ilicitud; un segundo momento como mera tolerancia, y un tercer momento, como derecho ${ }^{26}$,

23. GREZ TOSO, Sergio: Los anarquistas y el movimiento obrero. La alborada de "la Idea" en Chile: 1893-1915, Santiago de Chile: LOM Ediciones, 2007. Págs. 77 y ss.

24. MUÑOZ CORTÉS, Víctor: Sin Dios ni patrones, Santiago de Chile: Mar y Tierra ediciones, 2013. Pág. 37.

25. D’AURIA, Aníbal: "Introducción al ideario anarquista". En: AA.VV. El anarquismo frente al derecho: Lecturas sobre Propiedad, Familia, Estado y Justicia. Aníbal D’Auria. [et.al], Buenos Aires: Libros de Anarres, 2007. Pág. 45.

26. GAMONAL CONTRERAS, Sergio: Derecho Colectivo del Trabajo. 2a edición. Santiago de Chile: Abeledo Perrot, 2011. Pág. 367; TAPIA, Francisco: Sindicato en el derecho chileno del trabajo. Santiago de Chile: Ed. Lexis Nexis, 2005. Págs. 70-72;

Facultad de Derecho y Ciencias Sociales - Universidad de Valparaíso - Chile 
salvo la discrepancia que ha presentado César Toledo en sus estudios, respecto específicamente de la aplicabilidad de dicho tránsito histórico a la realidad chilena ${ }^{27}$. Salvando lo anterior, y en relación al último estadio histórico de la huelga (consagrada ahora como derecho) es posible sub-diferenciar dicho momento en dos: la consagración de la huelga como derecho de los trabajadores/organizaciones sindicales, en un primer momento, y la huelga como derecho fundamental, en un segundo.

La huelga desde una primera aproximación fenoménica, no jurídica aún, es la manifestación de una medida de presión que, termina siendo violenta en cuanto forma de imposición de poder $^{28}$ en una relación intersubjetiva. Cabe en este punto señalar y aclarar que todas las menciones a la huelga que estamos realizando son aquellas que comparten como criterio mínimo de distingo los elementos de ser presentadas colectivamente (asociación intersubjetiva) y reducida a aquellas que se dan en el contexto de relaciones laborales, por tanto dejamos fuera las "huelgas" individuales, incluyendo las huelgas de hambre que, por cierto, requerirían un análisis completo que ciertamente no podemos realizar en esta investigación, y dejaremos pospuesto como proyecto para un eventual análisis relacional entre derecho a resistencia y huelga.

La cuestión social transitó en Chile en la configuración de un sujeto colectivo desde un la mixtura del peonaje trasladado a la minas ${ }^{29}$, pasando por el mutualismo, hasta llegar a la configuración política del movimiento colectivo radicado esencialmente en tres organizaciones:

UGARTE CATALDO, José Luis y CAAMAÑO ROJO, Eduardo. Negociación colectiva y libertad sindical: un enfoque crítico. Santiago de Chile: Legal Publishing, 2008. Págs. 78-80.

27. TOLEDO CORSI, César: Tutela de la Libertad Sindical, Santiago de Chile: AbeledoPerrot, Legalpublishing, 2013. Pág. 276.

28. GAMONAL CONTRERAS, Sergio: Derecho Colectivo del Trabajo, ob. cit., p. 363; TAPIA, Francisco. ob. cit. p. 62.

29. SALAZAR, Gabriel: Labradores, peones y proletarios (Siglo XIX), cit. pp. 228 y ss. 
el partido democrático, los anarquistas y los movimientos socialistas ${ }^{30}$. El Derecho tradujo dicho conflicto a su lenguaje y a partir de 1924 comienza sistemáticamente con la dictación de leyes sociales.

En este contexto el derecho a huelga entra al discurso de los derechos a través regulación de una forma de ejercicio de poder, que tiene como finalidad el reequilibrio de fuerzas ${ }^{31}$, o bien, la búsqueda de reformulación o imposición de un modelo ${ }^{32}$. En el lenguaje del derecho ingresa como una instancia y reconocimiento de la autotutela ${ }^{33}$; un ejemplo de autotutela laboral que viene a reequilibrar una relación de poder en donde el trabajador, individualmente considerado se encuentra en una posición desmejorada respecto del empleador.

\section{La Huelga en el Derecho}

\section{a. La huelga como concepto jurídico indeterminado}

Tras el tránsito de la huelga como movimiento netamente fáctico de fuerza y poder, para algunos de defensa de condiciones mínimas de vida, para otros incluso de proyección de un horizonte emancipatorio en la relación utopía y sindicalismo ${ }^{34}$, ante el fenómeno de lo que se ha denominado "cuestión social", el Derecho incluye en sus filas a la huelga, y las organizaciones de trabajadores en general ${ }^{35}$ a fin de que

30. ANGELL, Alan. Partidos Politicos y movimiento obrero en Chile. Ediciones ERA, México, 1974, p. 33.

31. GAMONAL CONTRERAS, Sergio. "El derecho a huelga en la constitución chilena”. En: Revista de derecho (Coquimbo), 20(1), 2013. Pág. 108.

32. GAETE BERRÍOS, Alfredo. Manual de derecho del trabajo. Santiago de Chile: Editorial Jurídica de Chile, 1949. Pág. 260.

33. UGARTE CATALDO, José Luis y CAAMAÑO ROJO, Eduardo: Negociación colectiva y libertad sindical: un enfoque crítico. Pág. 80.

34. TANNENBAUM, Frank: Filosofía del trabajo. Santiago de Chile: Editorial del Pacífico, 1955. Traducción de Magdalena Santa Cruz. Págs. 76 y ss.

35. TOLEDO CORSI, César: ob. Cit. pp. 274 y ss.

Facultad de Derecho y Ciencias Sociales - Universidad de Valparaíso - Chile 
pueda dar una explicación no sólo sociológica del fenómeno o conflicto que se vivía entre empresarios o patrones y empleados u obreros, sino que a fin de que pudiese brindar una explicación en su propio lenguaje; el lenguaje del derecho.

Este tránsito institucionalizante ha sido estudiado por ciertos autores como una instancia a través de la cual el Estado cooptó un movimiento social popular cuya historia y trayectoria tenían un horizonte eminentemente emancipatorio de los sectores populares de la población ${ }^{36}$. Como se verá en lo que sigue, nuestra opinión es que la tipificación de la huelga (junto a la de las organizaciones de trabajadores) no representa sólo una posible cooptación del movimiento obrero, sino que su alcance modular va más allá, y tiene relación con la existencia misma del Derecho y su identidad inseparable, dialéctica y conflictiva con la violencia.

Codificado el Derecho del Trabajo, y regulado el funcionamiento de las organizaciones colectivas de trabajadores en sindicatos, la huelga viene a hablar en el mismo lenguaje del Derecho, para algunos aun contemporáneamente como "un mal necesario", o un medio instalado en un proceso particular de contratación como lo es el de la negociación colectiva, y que habría que evitar a través de todos los medios posibles.

Esta juridización de la huelga evidencia uno de los problemas insoslayables del Derecho, al menos en nuestra tradición continental ${ }^{37}$, cual es la indeterminación de un concepto jurídico. ¿Qué huelga fue invitada a habitar el derecho?; ¿existe alguna determinación de los caracteres fácticos que permiten calificar un conjunto de prácticas laborales como una "huelga"?

De manera general, creo que la afirmación de Duncan Kennedy es especialmente relevante y servirá de introducción, y conclusión anticipada, a la exposición que sigue:

36. SALAZAR, Gabriel: "Proyecto histórico social y discurso político nacional. Chile, siglo XIX”. En: Loyola, Manuel y Grez, Sergio (compiladores). Los proyectos nacionales en el pensamiento político y social chileno del siglo XIX. Ediciones UCSH, colección Monografías y Textos, Santiago, 2002, pp. 155 y ss.

37. HENRY MERRYMAN, John: La tradición jurídica Romano Canónica. Fondo de Cultura Económica, $2^{\circ}$ reimpresión, México, 1980, p. 13.

Revista de Ciencias Sociales - Número 70 (2017) - Universidad de Valparáíso - ISSN 0716-7725-Valparaíso, Chile 
"La pregunta "ontológica" es si es apropiado considerar la determinación de la norma aplicada a los hechos, es decir, su carácter insuperablemente vinculante o "válido" al final del periodo permitido para trabajar sobre ella, como su atributo propio, como alo inherente a ella”. La alternativa es que el carácter determinado o indeterminado de la norma no puede ser entendido más que como un "efecto", el "efecto de necesidad" o "efecto de determinación”, producido de manera contingente por la interacción del tiempo, la estrategia y la habilidad del intérprete con una incognoscible naturaleza "en sí" o "esencial" de la norma en el contexto fáctico dado" 38 .

Volviendo a nuestro objeto de estudio, a modo ejemplar en doctrina nacional se ha dicho que tradicionalmente la huelga se ha conceptualizado como "una abstención colectiva de trabajo" ${ }^{39}$, como "una manifestación esencial de la libertad sindical" tención en el cumplimiento de la obligación de trabajar, derivada de una situación de conflicto" ${ }^{41}$; como "el abandono o cesación temporal y colectiva del trabajo, acordado por parte de los asalariados, ya sea por causas económicas, de mejoramiento de las condiciones de trabajo, por solidaridad o por causas políticas, y que persigue como finalidad obtener de sus patrones o empleadores en los tres primeros casos, la alteración del contrato de trabajo, la modificación de las condiciones materiales en que la labor se desarrolla, el mantenimiento de determinados obreros o empleados o el respeto de los derechos que las leyes les otorgan, respectivamente, o bien, en el último caso el cambio del régimen económico y social existente o la transformación del Estado" ${ }^{42}$, o "uno de los medios

38. KENNEDY, Duncan: Izquierda y derecho. Ensayos de teoría jurídica crítica. Editorial Siglo XXI, Buenos Aires, 2010, p. 93.

39. GAMONAL CONTRERAS, Sergio: Derecho Colectivo del Trabajo, ob. cit., p. 369.

40. UGARTE CATALDO, José Luis y CAAMAÑO ROJO, Eduardo: Negociación colectiva y libertad sindical: un enfoque crítico. ob. cit., p. 79.

41. TAPIA, Francisco: ob. cit., p. 73.

42. GAETE BERRÍOS, Alfredo. ob. cit., p. 407.

Facultad de Derecho y Ciencias Sociales - Universidad de Valparaíso - Chile 
legítimos fundamentales de que disponen los trabajadores y sus organizaciones para la promoción y defensa de sus intereses económicos y sociales" como se señala en el informe anual de Derechos Humanos de la Universidad Diego Portales ${ }^{43}$, o "un derecho legítimo al que pueden recurrir los trabajadores y sus organizaciones en defensa de sus intereses económicos y sociales" o como "uno de los medios esenciales de que disponen para promover y defender sus intereses profesionales" como ha señalado el Comité de Libertad Sindical de la OIT $^{44}$ (y otros como César Toledo ${ }^{45}$ simplemente no otorgan una definición analítica del concepto, sino que más bien desarrollan su desenvolvimiento en el Ordenamiento Jurídico (lo mismo en gran medida Caamaño y Ugarte ${ }^{46}$ ).

La anterior enunciación ilustrativa arroja inmediatamente la primera gran tarea (complejidad) que conlleva el desarrollo de un estudio jurídico del derecho a huelga como derecho fundamental, incluso antes de adentrarse en el carácter iusfundamental del mismo. Existen amplias y diversas formas de conceptualizar la huelga por parte de la doctrina jurídica, desde una lectura más restringida a una más amplia, y sin duda quien crea detentar un derecho de ese tipo, ha de tener al menos un concepto del mismo, para poder contar con la certeza de encontrarse actuando legitimado por el derecho, y dentro de su ámbito de cobertura.

\section{b. Problemas de "delimitación interna" y "límites externos" al derecho a huelga: otra vez sobre el neoconstitucionalismo, y la idealización del juicio de ponderación}

Relacionado con lo anterior íntimamente, y en tránsito hacia su delimitación como derecho fundamental, se encuentra el segundo

43. Universidad Diego Portales: Informe anual sobre derechos humanos en Chile. Ediciones UDP, Santiago de Chile, 2014, p. 68.

44. OIT: La libertad sindical-Recopilación de decisiones y principios del Comité de Libertad Sindical del Consejo de Administración de la OIT. Quinta edición (revisada), 2006, p. 115.

45. TOLEDO CORSI, César. Ob. Cit.

46. UGARTE CATALDO, José Luis y CAAMAÑO ROJO: Eduardo: Negociación colectiva y libertad sindical: un enfoque crítico. ob. cit., pp. 81 y ss.

Revista de Ciencias Sociales - Número 70 (2017) - Universidad de Valparáíso - ISSN 0716-7725-Valparaíso, Chile 
escollo teórico. En un proceso de delimitación conceptual como el realizado a propósito de lo señalado en el párrafo anterior el interés de la Razón será definir evidentemente los límites internos, y distinguirlo a su vez de los límites externos ${ }^{47}$. Lo primero, pues la conceptualización del derecho a huelga no sería sino desarrollar el proceso de su delimitación; definir es encontrar los límites (que en este caso no serían sino internos). Luego, delimitado el derecho (encontrados los límites internos o inmanentes al derecho), siguiendo esta teoría, procedería encontrar otra dimensión que permitiese definir de manera exacta el contenido extenso del derecho, o en otros términos, el alcance del derecho, cual es la verificación de los límites externos del mismo. Ya no la mera constatación de lo que puede ser un posible contenido del derecho, sino que situados ya en ese lugar, evaluar cuáles serían los otros derechos, o las circunstancias de hecho, que representarían una contención o limitación de carácter externo al derecho de huelga. La antedicha distinción es especialmente útil a la "teoría de la ponderación" noción conflictualista de los derechos ${ }^{49}$, que presuponga que éstos pueden colisionar circunstancialmente, y que la solución a dicho enfrentamiento sería la determinación de una precedencia condicionada y contingente.

En el anterior sentido, Serna y Toller inician su análisis crítico de la posición conflictualista señalando en un primer momento que "desde una perspectiva conflictivista [...] la resolución a los conflictos pasa por trazar límites externos a los derechos. Así suele decirse que los derechos no son ilimitados, esto es, que tienen límites, entendiendo

47. GAMONAL CONTRERAS, Sergio: Derecho Colectivo del Trabajo, ob. cit., p. 11; TOLEDO CORSI, César. Ob. Cit. p.307; TAPIA, Francisco: ob. cit, pp. 81 y ss.

48. ALEXY, Robert: Teoría de los derechos fundamentales, trad. de Ernesto Garzón Valdés. Centro de Estudios Políticos y Constitucionales, Madrid, 2001, pp. 81

y ss.

49. ALDUNATE LIZANA, Eduardo: "Aproximación conceptual y crítica al neoconstitucionalismo". Revista de derecho (Valdivia), 23(1), 79-102, 2010, pp. 84 y ss.

Facultad de Derecho y Ciencias Sociales - Universidad de Valparaíso - Chile 
principalmente por tales no sus propias fronteras, sus contornos inmanentes o internos, sino ciertos factores externos de demarcación (...) ${ }^{" 50}$. En el mismo tono se ha pronunciado Ugarte al señalar que la base de la teoría neoconstitucionalista aplicada a los derechos fundamentales, entre los cuales se encuentran los laborales, o derechos específicos como el derecho a huelga, consiste en "distinguir entre dos momentos sucesivos en la delimitación del ámbito protegido de un derecho fundamental: primero, un ámbito prima facie cuyo contenido está protegido de modo inicial y provisional, y segundo, un ámbito definitivo de protección. Entre ambos momentos media, precisamente, la ponderación" ${ }^{51}$.

Sin perjuicio de lo anterior, es evidente que se puede optar por una teoría no conflictualista, en donde la determinación de los derechos se realice íntegramente en el primer momento de determinación interna, pero que a su vez dicha determinación interna se avoque a la situación concreta de hecho que se encuentra analizando ${ }^{52}$. Con ello se evitaría el uso retórico de un irrealizable uso de un proceso de ponderación supuestamente racional ${ }^{53}$.

En este sentido, resulta especialmente gravitante la circunstancia de ser considerado un derecho fundamental, pues en un contexto en donde predomina el neoconstitucionalismo ${ }^{54}$, el activismo judicial ${ }^{55} \mathrm{y}$

50. SERNA, Pedro y TOLLER, Fernando: La interpretación constitucional de los derechos fundamentales. Una alternativa a los conflictos de los derechos, La Ley, Buenos Aires, 2000, pp. 19 y ss.

51. UGARTE CATALDO, José Luis: "Los derechos en su nueva hora: la teoría externa de los derechos fundamentales". Revista de derecho (Coquimbo), 18(2), 361-373, 2011, p. 368.

52. KENNEDY, Duncan: ob. cit., p. 89.

53. GARCÍA AMADO, Juan Antonio: "El juicio de ponderación y sus partes. Una crítica”: En: Alexy, Robert (coord.), Derechos sociales y ponderación, Fundación Coloquio Europeo, Madrid, 2007.

54. NÚNEZZ POBLETE, Manuel A.: "El neoconstitucionalismo y el recurso a los valores en la jurisprudencia del Tribunal Constitucional chileno". Revista de derecho (Valparaíso), (34), 523-541, 2010, pp. 525 y ss.

55. GARCÍA, José Francisco y VERDUGO, Sergio. Activismo judicial en Chile Chile, 2013.

¿Hacia el gobierno de los jueces? Ediciones Libertad y Desarrollo, Santiago de

Revista de Ciencias Sociales - Número 70 (2017) - Universidad de Valparáíso - ISSN 0716-7725-Valparáíso, Chile

137 
las tesis principialistas, su entrada a la competencia en el "mercado de los derechos" lo enfrentará siempre a un segundo momento de delimitación (limitación externa) circunstanciada. Será tratado como un "derecho cenicienta" o un "derecho princesa"

Pero aun adhiriendo a la posibilidad de que el derecho de huelga pueda ser efectivamente ponderable de manera racional, y que el juicio de proporcionalidad o ponderación racional, en general, pueda ser realizado eficazmente, en contra de lo que afirman autores como García Amado y Estrada Vélez ${ }^{57}$ y como hemos afirmado también en otra investigación ${ }^{58}$, a pesar de aceptar que fuese posible su desenvolvimiento, en algún momento deberemos pronunciarnos sobre su contenido o limites internos. En este sentido será útil rememorar las posibles modalidades de su ejercicio, y las conceptualizaciones a las que hemos referido en el punto anterior, y con ello, su asociación a un contenido genérico como puede ser la perturbación "cualquiera" de la producción y funcionamiento de una empresa. Sin embargo, es evidente que bajo dicha concepción amplia del derecho a huelga (y de la huelga en sí, al fin y al cabo) aún podemos quedar con criterios de determinación incompletos. A tales efectos el criterio de interpretación teleológico puede ser de utilidad, pero una vez más deberemos adentrarnos en el contenido mismo del derecho de huelga y de la definición misma de huelga), y su delimitación interna para evaluar si una práctica efectiva en concreto se encuentra cubierta o no por el derecho fundamental a huelga.

En conformidad con lo anterior, vuelve a ser relevante el cuestionamiento de algo que pudo haber resultado desapercibido en líneas anteriores: ¿es el derecho a huelga un derecho fundamental autónomo? Esta pregunta se plantea en atención a su tradicional filiación tríadica

56. SERNA, Pedro y TOLLER, Fernando: ob. Cit., pp. 14 y ss.

57. ESTRADA VÉLEZ, Sergio: "La Ponderación o la débil frontera entre la arbitrariedad y el uso legítimo de la discrecionalidad". En: Revista Vniversitas. Bogotá (Colombia) N 121, julio-diciembre, pp. 77-112, 2010.

58. RUAY SÁEZ, Francisco: "Una crítica al juicio de ponderación de Alexy a propósito del procedimiento de Tutela Laboral”. En: Revista de Derechos

Fundamentales, Universidad de Viña del Mar, No 12, 2014, pp. 131 y ss.

Facultad de Derecho y Ciencias Sociales - Universidad de Valparaíso - Chile 
que históricamente le ha encadenado a otras dos garantías fundamentales que en todo caso parecen mucho más claras en su delimitación. Se trata de la vinculación tríadica del derecho colectivo de libertad sindical constituida por el derecho a negociación colectiva, el derecho a sindicalizarse (afiliarse y desafiliarse de un sindicato) y, obviamente, el derecho a huelga. Histórica y conceptualmente se ha afirmado que la libertad sindical no se encuentra efectivamente cubierta o lo suficientemente garantizada en un Estado y sistema jurídico determinado, si es que no se afianzan sustancialmente y de manera simultánea las tres garantías antedichas.

\section{c. Sobre si la huelga puede ser considerado un derecho fundamental autónomo}

Bajo el peso iusfundamental tríadico antes expuesto, ¿cuál sería la posición del derecho a huelga? Sin pretender extendernos en un análisis innecesario, podríamos a lo menos afirmar consistentemente que se trata de un derecho fundamental sin un contenido axiológico propio, sino que más bien, resulta ser una vehiculización en la realización de la garantía fundamental de libertad sindical. No es un derecho fundamental que tenga valor por sí mismo (la huelga no tiene un "valor" por ser huelga), sino que resulta relevante en cuanto pueda servir de realización efectiva de la libertad sindical. Pero cuidado. No es una relación contingente, sino que es de carácter necesario, o en otras palabras, la huelga no es huelga (se entiende dicho legítima) sino es la realización de la libertad sindical. Cualquiera otra acción humana colectiva que no permita su encuadre en esta figura simplemente no encuentra cobertura legal, al menos, en el tipo de huelga.

En otras palabras, la huelga es analizada y comprendida como un medio. ¿Pero un medio para qué? Un medio de empoderamiento de los trabajadores organizados colectivamente a efectos de negociar. Pero, nuevamente, ¿Negociar qué? Aquí vuelve a ser interesante la pregunta planteada.

Inexorablemente el carácter de derecho-medio del derecho fundamental a huelga sujeta la posibilidad de su verificación real no sólo a las acciones o prácticas objetivas que se verifiquen en el mundo

Revista de Ciencias Sociales - Número 70 (2017) - Universidad de Valparaíso - ISSN 0716-7725-Valparaíso, Chile 
social, sino que implica siempre un análisis respecto de los fines para los cuales ha de ser utilizado dicho medio. En ese sentido, el carácter de licitud viene en cierta medida también otorgado por este elemento teleológico, conforme al cual, situados en el primer momento de limitación interna, habrá que decidir si el ejercicio del derecho a huelga comprendería también la posibilidad de una acción colectiva que trascienda los intereses económicos, de salud y seguridad particulares de un grupo de trabajadores como en la definición de Gaete ${ }^{59}$. En otras palabras, ¿tiene cabida la huelga solidaria como huelga?; ¿̇es posible el ejercicio a huelga en la paralización de la empresa con fines políticos ${ }^{60}$ ?, ¿debe restringirse la huelga sólo a las reclamaciones por el resguardo de derechos y garantías al interior de la empresa en que laboran los trabajadores?, o, incluso, y en relación con la reforma laboral en actual trámite, ¿ puede la huelga no ser pacífica?, o en otras palabras, ¿es necesario predicar de la huelga que requiere ser "pacífica"?

La orientación a las respuestas posibles a las preguntas planteadas debe buscarse necesariamente recurriendo al análisis de contenido y alcance del derecho a huelga, como derecho fundamental, esto es, en la discriminación conceptual de los denominados límites internos y externos del derecho en cuestión. $\mathrm{Al}$ respecto podemos reenviar en cierto punto nuestra exposición a líneas anteriores en donde transcribimos en general la definición o conceptualización del derecho a huelga que realiza la doctrina nacional, e incluso los órganos internacionales competentes en la materia. Sin embargo, sí podemos aseverar que si bien ha sido reconocida en cierta medida la naturaleza autotutelar del derecho de huelga, dicha comprensión implica simultáneamente su carácter excepcional por contemplar una situación marginal de "autorización" de uso legítimo de fuerza ${ }^{61}$ por una de las partes con-

59. GAETE, Alfredo. ob. cit., p. 260.

60. Obviamente suponiendo que la delimitación interna del derecho a huelga queda fijada previo a la tipificación legal de la misma, o sea, que sería pensable que la ley al fijar un límite, como la prohibición de la huelga política, en realidad estaría vulnerando indebidamente el derecho a huelga, pues la huelga en sí contiene la posibilidad se ponerse como finalidad el alcance de un logro político.

61. Cabría ver hasta qué punto el ejercicio de éste derecho puede limitar otro o refiere a un acto situado en un lugar fuera del Derecho.

Facultad de Derecho y Ciencias Sociales - Universidad de Valparaíso - Chile 
tratantes, sin la intermediación del Estado (quien habría, en principio, monopolizado el uso de la fuerza o violencia). Pero aun así, aunque se trate de un ejercicio autotutela con una finalidad de reequilibrio de fuerzas en posiciones constitutivamente en desequilibrio ${ }^{62}$, su realización práctica o el ejercicio del derecho fundamental en cuestión suponen siempre y en todo momento como un límite de carácter absoluto el resguardo del orden público y la actuación, al final del día, de un "derecho" fundamental, que como tal, supone un ejercicio pacífico. En otros términos, el ejercicio del derecho fundamental de huelga es, por definición, un ejercicio "pacífico", en el sentido de que en la actuación de cualquier derecho el Estado sitúa un momento de paz social, no abriendo la posibilidad a la mera violencia arbitraria. No sería necesario, en principio, añadir la expresión "pacífica" al ejercicio del derecho fundamental de huelga, porque este calificativo se presenta a lo menos en los dos momentos analíticos de determinación de límites internos y externos del derecho fundamental a huelga.

Precisamente la formulación del derecho fundamental a huelga como un derecho de tal naturaleza, y la posibilidad de resolver su interacción con otros derechos a través de un "método racional de ponderación" permite profundizar la claridad sobre este alcance. Podríamos afirmar que el derecho a huelga, aún más que otros derechos fundamentales, constitutivamente, en su formulación más básica ${ }^{63}$ ya interfiere en la realización del derecho de un tercero. Su conceptualización fundamental implica necesariamente la existencia del derecho de un tercero que será limitado o, a lo menos, perturbado.

Teóricamente se plantea un problema evidente. De seguir el trayecto alexiano de la ponderación se nos presenta la condición paradójica de que al analizar el posible conflicto de derechos fundamentales entre el derecho a huelga y otro necesariamente conflictuado, como puede ser el derecho de propiedad del empleador o de libertad

62. GAMONAL CONTRERAS, Sergio: Derecho Colectivo del Trabajo. ob. cit., p. 364. Lo importante no es sólo el desequilibrio, sino antes la posición de poder de uno sobre el otro.

63. Como mera perturbación.

Revista de Ciencias Sociales - Número 70 (2017) - Universidad de Valparaíso - ISSN 0716-7725-Valparaíso, Chile 
económica ${ }^{64}$, por ejemplo nos encontramos en la disyuntiva del momento de determinación de los posibles límites que permitan analizar la medida en concreto $^{65}$; ¿hasta dónde la huelga es huelga? Necesariamente requiere una evaluación previa de su contenido, y dicha apreciación se relaciona íntimamente con las posibilidades de restricción de los derechos del empleador. Por ejemplo, si la medida adoptada por el Sindicato es la de suspender su prestación de servicios respecto del empleador, podemos señalar que se trata de una medida idónea o adecuada, necesaria y proporcional en sentido estricto, en su interacción con el derecho de propiedad del empleador. Pero ahora, ¿̇la obstrucción a los ingresos y salidas de una fábrica, son parte limitan desproporcionadamente el derecho de propiedad del empleador?; ¿̇la destrucción de la propiedad privada de la empresa, los bloqueos de ingresos respecto de clientes del empleador, prohibición de ingresos de trabajadores que no se encuentren participando activamente en huelga por no ser parte del sindicato, aquellas prácticas, representan limitaciones desproporcionadas de los derechos del empleador? ¿Puede señalarse siquiera que en aquellos casos también existe una protección prima facie?

Inmediatamente se nos presenta otro problema de suma relevancia. A efectos de sujetar el citado derecho fundamental de huelga al balancing test, esto es a un juicio de proporcionalidad, debemos subir a la balanza al derecho de huelga mismo, sin embargo, ¿ puede el derecho a huelga presentarse como derecho autónomo a efectos de ser ponderado o balanceado? Esta pregunta tiene una relación estrechísima con el sitial que ocupa la huelga en la tríada constitutiva de la libertad sindical, junto a la negociación colectiva, y el derecho a sindicarse. Por eso, lo relevante a fin de responder esta pregunta será previamente escudriñar

64. UGARTE CATALDO, José Luis: "Los derechos en su nueva hora: la teoría externa de los derechos fundamentales". Revista de derecho (Coquimbo), 18(2), 361-373, 2011, p. 366.

65. En este caso en el análisis con aplicación del juicio de ponderación la "medida" analizada sería la acción adoptada por el titular del derecho a huelga respecto de quien es vulnerado en alguna garantía, o sea, el empleador (RUAY SÁEZ, Francisco: ob. cit., p. 136).

Facultad de Derecho y Ciencias Sociales - Universidad de Valparaíso - Chile 
la naturaleza de cada uno de los elementos de la tríada tradicional: ¿se trata de derechos en sí, de formas de presentación de otro derecho (libertad sindical), o en general, se trata de meros medios de realización de un derecho fundamental Otro? Evidentemente una u otra opción, al momento de subir a la balanza, determinar u orientaran el desarrollo de la argumentación jurídica racional en un sentido determinado. Si pensamos en la huelga como derecho autónomo, podría configurarse ésta como mero derecho a paralización o perturbación de una determinada faena. En ese sentido queda un tanto insustancial su contenido, y el llamado a la ponderación, en sus tres episodios (adecuación, necesidad y proporcionalidad en sentido estricto) queda desprovisto de horizonte de realización. No hay un derecho respecto del cual se pueda tener referencia (ni siquiera en una protección prima facie) para verificar si una medida concreta fue idónea o no; dicho contenido vendría dado en realidad por un derecho que contendría a la huelga como medio de realización del mismo.

Quienes pretenden sostener que la teoría alexiana tendría plena aplicación en nuestro ordenamiento jurídico, como los profesores José Luis Ugarte ${ }^{66}$, Sergio Gamonal ${ }^{67}$, Daniela Marzi ${ }^{68}$ y Eduardo Caamaño ${ }^{69}$, por solo nombrar a algunos, debiesen otorgar herramientas

66. UGARTE CATALDO, José Luis: "Los Derechos Fundamentales del Trabajador: el nuevo procedimiento de tutela laboral”, Colección Ensayos Jurídicos, Universidad Alberto Hurtado, No 2, 2006; UGARTE CATALDO, José Luis: "La constitucionalización del derecho del trabajo: la tutela de derechos fundamentales". En: Revista Latinoamericana de Derecho Social, No 7, julio-diciembre de 2008, 2008.

67. GAMONAL CONTRERAS, Sergio: Ciudadanía en la empresa o los derechos fundamentales inespecíficos. Fundación de Cultura Universitaria, Editorial Jurídica, Uruguay, 2004.

68. MARZI, Daniela: “¿Quién le teme a los derechos fundamentales? Sobre el procedimiento de tutela de la Reforma Laboral”. En: Anuario de Derechos Humanos, $\mathrm{N}^{\circ}$ 6, 2010, p. 134.

69. CAAMAÑO ROJO, Eduardo: "La eficacia de los Derechos Fundamentales en las relaciones laborales y su reconocimiento por la Dirección del Trabajo". En: Revista de Derecho de la Pontificia Universidad Católica de Valparaíso. Vol. XXVII, Semestre I, 2006.

Revista de Ciencias Sociales - Número 70 (2017) - Universidad de Valparáíso - ISSN 0716-7725-Valparáiso, Chile 
consistentes para posicionar un derecho fundamental como el de huelga en la balanza del mercado de derechos fundamentales en competición de manera autónoma, o de lo contrario, calificar claramente el estatuto o naturaleza jurídica del derecho en cuestión, en tanto principio evidentemente no autónomo, y sin primacía prima facie.

Por último, sin concebirlo como derecho autónomo, tampoco podríamos sostener consistentemente que el derecho fundamental de huelga efectivamente colisionaría (valga decir: externamente) con otro derecho ${ }^{70}$. En efecto, el derecho a huelga quedaría en gran medida desprovisto de un contenido propio que se enfrente a otro derecho a fin de lograr una preponderancia condicionada y contingente tras la aplicación del método de ponderación y los subprincipios que lo constituyen. Lo que inevitablemente habría que realizar es recurrir teóricamente a la libertad sindical como derecho fundamental cimiente, y retóricamente vincular el contenido del derecho de huelga con las finalidades legítimas de la libertad sindical, a fin de evaluar las posibilidades de resultar vencedor en un terreno conflictual.

El mayor problema que conlleva la juridización del derecho a huelga es que en tanto tal es un derecho constitutivamente limitador de derecho ajeno ${ }^{71}$ y bajo un paradigma neoconstitucionalista no existe la posibilidad de desplegar la ponderación en abstracto, sino sólo "una relación condicionada de precedencia" 72 sujeta a las particularidades fácticas de la medida sujeta a evaluación. No es posible (ni deseable) establecer una precedencia incondicionada de garantías fundamentales (y valores, al fin y al cabo) entre $s^{1}{ }^{73}$, sino que la ponderación y la real eficacia de los derechos fundamentales viene recién a realizarse y mani-

70. Ya analizamos en parte este problema a propósito de los límites interno y externos del derecho

71. Pero también de bienes jurídicos de trascendencia que no son propiamente derechos subjetivos como el Orden público, la seguridad por ejemplo (Caamaño y Ugarte, 2008, p. 88).

72. ALEXY, Robert: ob. cit., p. 157.

73. Ibíd. pp. 152 y ss.

Facultad de Derecho y Ciencias Sociales - Universidad de Valparaíso - Chile 
festarse en aquellas situaciones en que un caso concreto, con una medida precisa sujeta a análisis, nos llaman al estudio de su proporcionalidad circunstanciada. Por lo mismo se ha afirmado tan certeramente que es muy probable que en un caso particular y contingente dichos derechos venzan, pero en otros decididamente pierdan; no siempre son cartas de triunfo, algunas veces serán derechos princesa, en otras derecho cenicienta.

\section{d. Los problemas de titularidad y ejercicio del derecho, bajo el paradigma de los derechos subjetivos}

Ahora bien, el ejercicio mismo del derecho de huelga, como derecho sindical, representa también un problema teórico. Se trata de un derecho de titularidad individual pero de ejercicio colectivo. En esto se diferencia de la general libertad sindical que siempre contará con una faz de ejercicio individual (aunque, como ya dijimos, puede ser una representación de la misma). Ésta (la libertad sindical) permite una protección individual evidente cual es la posibilidad de afiliarse (o conformar originariamente) o desafiliarse de un sindicato; la libertad sindical contiene una faz positiva y una negativa, en tanto libertad. Pero la huelga, ¿qué modalidad de ejercicio individual reconoce al titular? Al sujetar su forma de realización a las formas de elección o votación contempladas en la ley ${ }^{74}$, si la voluntad colectiva decide optar por la realización de la huelga, evidenciamos su ejercicio como derecho fundamental. Sin embargo, ¿qué paso con quien votó desistir de la huelga? Diremos: él también se encuentra en huelga, pues el ejercicio del derecho a huelga supone una elección mayoritaria y su ejercicio inicial en el acto de votación lo vincula para lo que continúa. ¿Pero y si el trabajador simplemente no comparte la decisión del sindicato y no desea ir a huelga, ni activa ni pasivamente, sino que es su interés reintegrarse a sus labores? En abstracto podríamos decir que existe nueva-

74. $\mathrm{Al}$ menos en nuestro ordenamiento jurídico, en que la Huelga se sitúa sólo en el proceso de negociación colectiva reglada, con un procedimiento de llamado a votación, de votación misma y comunicación altamente formalizado, contemplado en los artículos 369 y siguientes del Código del Trabajo.

Revista de Ciencias Sociales - Número 70 (2017) - Universidad de Valparáíso - ISSN 0716-7725-Valparaíso, Chile 
mente un conflicto de derechos (para quienes sostienen que sería aplicable dicha doctrina), o bien, desde ya podremos afirmar claramente que ante la ley se está restringiendo ilegítimamente su libertad de trabajo, de la cual es titular individualmente, o bien, incluso, si queremos sostener lo contrario, podemos señalar que lo que opera es simplemente el derecho a huelga, que no requiere "el consentimiento individual" más que en el acto decisiorio inicial, y que re-absorbe las voluntades individuales en el colectivo que toma sustancia en la dinámica negociadora; lo relevante en este caso resulta ser sólo "el consentimiento colectivo", y por lo mismo, desde el inicio de su ejercicio, la voluntad individual pasa ser absorbida por el colectivo triunfador, no quedándole más, que por orden misma del Derecho, conformarse con acatar jurídicamente, "de pleno derecho" las consecuencias de su acto conforme al cual por ficción se entiende que se encuentra haciendo ejercicio de su derecho fundamental a huelga. Situaciones como la expuesta se encuentran solucionadas a través de la ley, en nuestro caso, prohibiendo el reintegro, y siendo el legislador quién ha supuesto que en el fondo efectivamente es la voluntad del colectivo la que ha de ser oída, y que de pleno derecho, el trabajador, titular del derecho a huelga, se encuentra haciendo ejercicio del derecho colectivo a huelga.

Lo anterior no deja de ser relevante toda vez que autores como José Luis Ugarte y Caamaño ${ }^{75}$ o César Toledo ${ }^{76}$ han señalado expresamente que el legislador se ha erigido como uno de los principales agresores de la garantía iusfundamental. Dicha afirmación supone al menos dos cosas. En primer lugar, que hay un contenido de la huelga que trascendería su regulación legal, o sea, ante el cual podría ponerse en comparación lo tipificado en nuestro ordenamiento jurídico, y de cuyo contraste podríamos señalar que es armónico, y por tanto que se respeta el derecho de huelga, o por el contrario, que la norma legal o contraría o restringe impropiamente dicha garantía, por lo que podríamos señalar que la norma legal sería contraria al derecho a huelga. Sin embargo, simultáneamente supone también que existe alguna

75. UGARTE CATALDO, José Luis y CAAMAÑO ROJO: ob. cit., p. 80.

76. TOLEDO CORSI, César: ob. cit., p. 292.

Facultad de Derecho y Ciencias Sociales - Universidad de Valparaíso - Chile 
norma que consagra el derecho a huelga como derecho fundamental en nuestro ordenamiento jurídico, y que debiese ser en dicha norma de jerarquía superior en cuya referencia el legislador habría de desplegar su actividad nomogenética.

Ambos presupuestos caen, tras desarrollar un análisis completo de la huelga en nuestro ordenamiento jurídico. En primer lugar, no existe ninguna norma jurídica vigente que consagre un contenido posible, claro y distinto, del derecho a huelga como derecho fundamental. Los alcances del mismo no son más que elucubraciones que no se desprenden necesariamente de un texto jurídico vinculante. Aun aceptando la tesis de Ugarte y Caamaño ${ }^{77}$, y que ha sido sostenida también por la Corte Suprema, en el contexto de lo que se ha denominado bloque de constitucionalidad ${ }^{78}$ de que puede deducirse que se encuentra consagrado implícitamente el derecho a huelga en la Constitución, seguimos igualmente sin tener a disposición ningún contenido claro. Por otra parte, lo que sí se contempla, incluso a través de la inclusión del bloque de constitucionalidad por la remisión del artículo $5^{\circ}$ inciso segundo de la Constitución, es la consagración en el Pacto Internacional de Derechos Sociales, Económicos y Culturales, en su artículo $8^{\circ}, \mathrm{n}^{\circ} 1$, letra d), que señala que "Los Estados Partes en el presente Pacto se comprometen a garantizar: d) El derecho de huelga, ejercido de conformidad con las leyes de cada país”.

En otras palabras, desde la aplicación correcta del principio de juridicidad, es posible señalar que si bien no existe una consagración explícita del derecho a huelga como derecho fundamental en la Constitución, sí es posible señalar que por la remisión hecha por la Constitución al PIDSEC, el derecho a huelga tiene vigencia en nuestro ordenamiento jurídico, pero, en todo caso, y tal como señala el propio instrumento internacional, en conformidad a las leyes de cada país. Aquello parece razonable, más aún cuando no existe una concep-

\footnotetext{
77. UGARTE CATALDO, José Luis y CAAMAÑO ROJO: ob. cit., p. 79.

78. NOGUEIRA ALCALÁ, Humberto: "El bloque constitucional de derechos en Chile, el parámetro de control y consideraciones comparativas con Colombia y México: doctrina y jurisprudencia”. En: Estudios constitucionales, 13(2), 301-350, 2015, p. 323.
}

Revista de Ciencias Sociales - Número 70 (2017) - Universidad de Valparáíso - ISSN 0716-7725-Valparáiso, Chile 
tualización abstracta clara de qué se quiere significar cuando se dice "huelga". Por lo mismo, su ampliación a casos incluso fuera de la relación laboral tradicional, o que escarpe al procedimiento de negociación colectiva, se vuelve aún mucho más espuria. En todo caso, esto no viene más que a ser una nueva muestra de lo dificultoso que es contornear, o siquiera intentar vislumbrar la silueta de un derecho espectral como el derecho fundamental a huelga.

\section{e. La huelga como derecho fundamental, la ciudadanía en la empresa y democracia}

Por último, puede relacionarse directamente la consagración del derecho a huelga como derecho fundamental con la idea del ingreso de la ciudadanía en la empresa ${ }^{79}$. Si bien se ha asociado en la mayoría de los casos dicha noción con la idea de que los trabajadores ingresan a su lugar de trabajo bajo el alero proteccionista de las garantías iusfundamentales que no son propiamente laborales ${ }^{80}$, también es verdad que en el contexto actual, todo este ingreso iusfundamental y su eficacia horizontal ante el empleador han sido visto como un avance progresista orientado a la democratización general de la sociedad ${ }^{81}$ (Baylos, 2011) (Ugarte, 2014). El respeto del derecho a huelga, como derecho fundamental, no sólo sería entonces un compromiso con los derechos laborales, sino que trasciende este ámbito, y podría afirmarse que la cautela y el ejercicio efectivo de dicha garantía fundamental es un indicio óptimo de democracia en un país cualquiera de occidente. La posibilidad de que los trabajadores puedan hacer efectivo el derecho a huelga es manifestación e índice de democracia de una sociedad cualquiera.

$\mathrm{Al}$ respecto, nuevamente, cabe volver sobre la posibilidad de un análisis teleológico de la garantía iusfundamental en cuestión. Así,

79. GAMONAL CONTRERAS, Sergio: Ciudadanía en la empresa o los derechos fundamentales inespecíficos. Ob. cit.

80. CAAMAÑO ROJO, Eduardo: ob. cit.

81. BAYLOS GRAU, Antonio Pedro. "Estado democrático de Derecho y amplio reconocimiento del derecho de huelga". Derecho laboral: Revista de doctrina, jurisprudencia e informaciones sociales, No 242, 2011, pp. 285-292, 2011.

Facultad de Derecho y Ciencias Sociales - Universidad de Valparaíso - Chile 
dependiendo del contenido del derecho fundamental podremos hacer un diagnóstico acertado sobre el alcance político-jurídico que acarrea la eficacia de un derecho fundamental cualquiera, y en este caso, del derecho a huelga en particular. Pero nuevamente, ¿̇cuál es la finalidad del derecho en cuestión?

Si nos reducimos la vinculación de la huelga a la negociación por mejoras particulares de los trabajadores en el contexto de un empresa, sin trascendencia que rompa el vínculo trabajador(es)-empleador, podría afirmarse que su eficacia efectiva es un aporte a la democracia, y al Estado de Derecho, en cuanto permite sostener la idea de que es posible negociar o suscribir acuerdos en posiciones de igualdad (aunque una de las partes tenga que artificialmente constituirse como un ente colectivo para efectos del ejercicio de la garantía), y así, la promesa liberal de horizontalidad de las relaciones jurídicas, gracias a la artificialidad del contrato, se ha equilibrado. Pero dicha conclusión parece venir de un razonamiento a todas luces tautológico: la protección del derecho resulta ser positiva porque en sí mismo el contenido de ese derecho es bueno; la eficacia del derecho a huelga (habiendo definido cuál era el contenido, posibilidades y finalidades de la misma) es un índice de salud de una determinada sociedad, precisamente porque se cautela dicho derecho en todas sus dimensiones. Sin embargo, aquello no es más que afirmar que un Estado de Derecho es tal porque es un Estado que está sujeto al Derecho. O en otros términos, lo único que permitiría predicar la vigencia y eficacia del derecho fundamental a huelga es la realidad de su propia eficacia. El Derecho se ufana de que pueda seguir siendo Derecho en su práctica efectiva; de lograr ser eficaz. La huelga, al estar desprovista de contenido es un índice instrumental de estado "democrático" de una sociedad de carácter tautológico, toda vez que "la" huelga que está sujeta a evaluación, es sólo la propia huelga que el Derecho permite para sí. Es una prueba que sólo se mide a sí mismo, lo que en todo caso no es excepcional.

Por otro lado, la novedad no debiese ser tal. La eficacia y vigencia del derecho fundamental a huelga no puede, ni tiene por qué ser un índice diverso de logro democrático en una sociedad, en diferencia a cualquier otro derecho fundamental. El Estado de Derecho debe velar porque todo derecho resulte al final del día eficaz, a fin de alcanzar la 
plenitud de su legitimidad, y la circunstancia de la tipificación o codificación, en general, de cualquier otro derecho, en cualquier instrumento que integre un ordenamiento jurídico concreto, implica un imperativo categórico dirigido a sí mismo conforme al cual debe velar por la vigencia efectiva de todos los derechos que lo realizan; la aplicación del Derecho y su eficacia representarán su propio anhelo de conservación. He ahí la incondicionalidad de hacer suya toda violencia, y vocalizarla en el lenguaje de los derechos. Es aquello precisamente lo que ha sucedido con el derecho a huelga; que de Otro del Derecho, pasó a ser tolerado, para ahora, incluso, a ser índice de democratización social (aunque de todas formas la apertura brindada por el concepto de democracia nos deja en una posición similar).

\section{LA HUELGA, LA VIOLENCIA, Y LA VIOLENCIA DEL DERECHO}

En las líneas que siguen pretendemos valernos de las exploraciones teóricas desarrolladas por Walter Benjamin en sus reflexiones sobre la violencia y el derecho contenidas de manera esencial en el texto "Para una Crítica de la violencia" 82.

Tal como esclarece Judith Butler en su texto "Walter Benjamin y la crítica de la violencia", éste "ofrece por lo menos dos relatos distintos. En una primera instancia, su pregunta es: ¿̇ómo es que la violencia legítima se hace posible? ¿Qué hace que la ley precise violencia $-\mathrm{o}$, al menos, un efecto coactivo- para hacerse vinculante? Pero también: ¿Por qué puede la violencia asumir una forma legal" ${ }^{83}$.

Benjamin pretende realizar un análisis directo de la violencia, en cuanto tal, y para aquello "la crítica puede circunscribirse a la descripción de la relación de ésta respecto del derecho y a la justicia" ${ }^{\text {4 }}$.

82. BENJAMIN, Walter: Para una crítica de la violencia y otros ensayos, Iluminaciones IV, Introducción y selección de Eduardo Subirats. Traducción de Roberto Blatt, Taurus, Madrid, 1991.

83. BUTLER, Judith. ¿A quién le pertenece Kafka?. Palinodia, Santiago de Chile, 2014, p. 64.

84. BENJAMIN, Walter: ob. cit., p. 23.

Facultad de Derecho y Ciencias Sociales - Universidad de Valparaíso - Chile 
Aquello sin duda entronca directamente con la ley, la ley de las leyes y los caracteres del Derecho. Tradicionalmente las formas de aproximación, lectura y crítica de la violencia se han situado en una de dos posiciones, que comparten un eje fundamental común: situar a la violencia como medio. Entendida la violencia como medio "de" o "para", una crítica que verse sobre la misma no puede escapar para el análisis de su carácter de tal, y por lo mismo, o bien se le juzga como "justa" en la medida que su carácter de medio se vincula teleológicamente con un fin trascendente que es calificado como justo, o puede afirmarse que es "legítima" en cuanto conserva coherencia con las disposiciones normativas que le delimitan. La primera lectura se asocia tradicionalmente con lo que se ha denominado en filosofía del Derecho la tradición "iusnaturalista". Al definir unos objetivos ciertos como justos y deseables por todos, los medios que puedan vincularse causalmente como idóneos para alcanzar dicho objetivo pueden ser calificados como justos. En ese sentido, existe la posibilidad de invocar la violencia en nombre de la justicia, y por lo mismo, calificarla de violencia justa, precisamente por el bien trascendente que permitirá resguardar o hacia el cual proyecta su alcance.

Por otra parte, la violencia puede ser calificada de legítima sólo si se corresponde con alguna medida previamente contemplada por el mismo ordenamiento jurídico; aquí existe un juicio de adecuación ya no respecto de un fin trascendente, sino en relación con lo que la propia ley, y en general, el Derecho, ha consagrado y promulgado como Derecho legítimo. Hay violencia legítima sólo si los medios respetan el principio de juridicidad, si la violencia es jurídica, y puede traducirse como Coerción ${ }^{85}$. No existe un lugar anterior ni superior al propio ordenamiento, sino que cualquier actuación ha de ordenarse a lo dispuesto por aquél, y en ese sentido puede predicarse de la misma que sería legítima.

En la anterior exposición nos encontramos aún en el reino de los fines y de los medios ${ }^{86}$, y la oposición aparente entre derecho positivo y

85. NINO, Carlos Santiago. ob. cit., p. 171.

86. RUIZ GUTIÉRREZ, Adriana María: "Walter Benjamin: una crítica a la violencia del derecho". Revista Estudio de Derecho, Universidad de Antioquia. Vol. 69, No 153, 2012, Rescatada en: http://aprendeenlinea.udea.edu.co/revistas/ index.php/red/article/view/14141/12501, p. 72.

Revista de Ciencias Sociales - Número 70 (2017) - Universidad de Valparáíso - ISSN 0716-7725-Valparáiso, Chile 
derecho natural resulta evidente. Sin embargo, si bien una supuesta crítica de la violencia, en general, se puede vincular inexorablemente al reino de los fines justos, por su parte resulta ser la legalidad el criterio de los medios. La falencia de una crítica de esta naturaleza salta a la vista: "si bien es cierto que el derecho positivo está ciego en materia de incondicionalidad de los fines, el natural lo está igualmente respecto al condicionamiento de los medios" ${ }^{87}$. "No obstante, y sin obviar las oposiciones, ambas teorías comparten un dogma fundamental: que los fines justos pueden ser alcanzados por medios legítimos y, a la par, los medios legítimos pueden ser utilizados al servicio de fines justos. Por consiguiente, el derecho natural aspira a "justificar" los medios por la justicia de sus fines; y el derecho positivo, en cambio, intenta "garantizar" la justicia de los fines por la legitimación de los medios" $"$.

El problema de la dicotomía tradicional antes expuesta es que quedamos en realidad atrapados en una crítica de la violencia, que no la aborda nunca directamente sino siempre de manera esquiva y eminentemente retórica. Lo realmente importante son los fines, los juicios de adecuación que en relación a los mismos siempre podrán ser compelidos a servirles, y lo justo de la violencia no estará contenido en la violencia misma, no podrá ser analizado de manera "pura" sino suspendido en la realización de un algo otro que nunca acaba de llegar. Pero "la legalidad" tampoco nos dice mucho, la descripción normativa de las hipótesis de violencia y la adecuación de las acciones efectivamente acaecidas en la práctica a dichas prescripciones vuelven indiferente la mirada hacia los fines, permitiendo tal laxitud que la violencia queda incondicionada por su carácter pre-normativo, y la crítica sobre los medios es en realidad una crítica sobre los mismos medios, y su "justeza" con el Derecho, más no una posibilidad de crítica de la violencia. Pero entonces, ¿hay posibilidad de trascender esta crítica dicotómica de sumisión del análisis de la violencia al derecho positivo (sin contenido determinado) o la justicia de los fines (sin control de medios)? Parece que Benjamin nos invita aquello.

87. BENJAMIN, Walter: ob. cit., p. 25.

88. RUIZ GUTIÉRREZ, Adriana María: ob. cit., p. 73.

Facultad de Derecho y Ciencias Sociales - Universidad de Valparaíso - Chile 
En este primer apunte de las ideas de Benjamin ya obtenemos herramientas relevantes para el análisis de la huelga, y del ejercicio del derecho a huelga como posibilidad de la violencia. La lectura de la huelga como medio y su vinculación inexorable a un fin que le trasciende, justifique y otorgue contenido, permite encontrar en su discurso el mismo discurso que el de la violencia, en general, y sus posibilidades de análisis del Derecho. En otras palabras, podremos aquí traspasar las conjeturas elaboradas por Benjamin a propósito de la dicotomía derecho natural-derecho positivo: en el derecho a huelga, como medio, su legitimación, o la crítica de su efectividad jurídica pasa por analizar si la huelga ha de conectarse con algún fin trascendente, y en tal caso, tal como señalamos en los puntos anteriores, quedamos sujetos a la justicia de dichos fines en todo caso de análisis de la huelga misma. La huelga, tal como la violencia en general, se sostendrá como justa-legítima (debiésemos señalar aquí, propiamente jurídica o sujeta al principio de juridicidad) en tanto el fin al que propugne sea justo. Sin embargo, tal como hemos expuesto en el capítulo anterior, el fin mismo de la huelga no está fuera de sí, parece que no hay una posibilidad de análisis de la huelga en un sentido "puro", si no es mirando a la finalidad (el logro de beneficios económicos particulares para los trabajadores de una empresa en particular, la negociación de beneficios o jornadas, la protesta por condiciones de salubridad de los trabajadores, el comunismo, el derrocamiento del Estado, la obtención del poder político, etc.). Tal como en el caso de la violencia, la huelga se vuelve volátil como entidad autónoma bajo esta lógica iusnaturalista propia del mundo de los fines.

Pero por otro lado, tampoco resulta esclarecedora la crítica que sujeta el análisis de la huelga, sus alcances y consistencias, a un análisis neto de su juridicidad o legitimidad como medio. Aquí puede que encontremos una diferencia aparente con el análisis de la violencia en una crítica pura; la huelga prescrita en la ley, con palabra de ley, puede ser calificada de legítima en tanto es un medio congruente con el principio de juridicidad. Es un medio justo, respecto del cual, en principio resultaría indiferente el carácter o tono de sus fines exteriores; basta una análisis formal para determinar su legalidad y por consiguiente su legitimidad, quedando suspenso un juicio sobre la justicia de la misma,

Revista de Ciencias Sociales - Número 70 (2017) - Universidad de Valparáíso - ISSN 0716-7725-Valparáiso, Chile 
a menos que estimemos que aquello que es decretado con fuerza de ley, por definición misma del Derecho, es lo justo. En palabras de Ricœur: "el lugar de la justicia se encuentra así delineado como parte del conjunto de opciones que una sociedad opone a la violencia, conjunto que define el Estado de Derecho" ${ }^{89}$.

Esta primera aproximación nos sitúa aún en el mismo lugar. Resulta ser una aporía la calificación de justicia ${ }^{90-91}$ referida a la huelga porque nos sitúa en la indiscernible situación de escoger la justicia de los medios o de los fines (nunca la propia justicia), escondiendo tras de sí su experiencia de lo imposible. Si la huelga es uno de tantos medios, bastan los fines justos para sostener que los medios también lo son; si se enaltece el fin, la huelga y su carácter violento pasan a sujetar la posibilidad de su crítica a la justicia del primero: el mero medio sujeta su calificación al fin. Siempre que podamos adecuar el medio (huelga) al fin perseguido (político, económico o social) vamos a poder construir retóricamente la estructura conforme a la cual la huelga o el eventual ejercicio de la violencia, o la comprensión de la huelga como intrínsecamente violenta, pasa a ser comprendida como un fenómeno necesario.

Pero cuidado. Puede pensarse que es posible alcanzar coherencia entre el reconocimiento de un fin justo y medios legítimos, simultáneamente. Pero aquello no pasa de ser una forma inconsciente de evadir una relación de precedencia manifiesta, en donde la legitimidad, legalidad o juridicidad de la actuación o medida resulta ser el valor resguardado primordialmente, antes que el fin mismo que, sólo retóricamente ha sido calificado como justo. Entonces, al adoptar aquella decisión de lectura teórica, que en apariencia es la más razonable ${ }^{92}$, ¿qué es en realidad lo que está sucediendo?

89. RICCEUR, Paul. Lo Justo. Editorial Jurídica de Chile, Santiago de Chile, 1997, p. 187.

90. DERRIDA, Jacques: Fuerza de ley. El "fundamento místico de la autoridad. Tecnos, Barcelona, 2008, p. 39.

91. "Justicia es una experiencia de lo imposible".

92. Siempre en Derecho las soluciones intermedias parecen ser las "más ajustadas a derecho".

Facultad de Derecho y Ciencias Sociales - Universidad de Valparaíso - Chile 
La relación entre la violencia y el Derecho, tal como se puede desprender de lo expuesto en líneas anteriores, es de alteridad constitutiva. No existe violencia sin Derecho, y no existe Derecho (ni derechos) sin violencia. Así lo evidencia, por ejemplo, Jean Paul Sartre, en el análisis de las pretensiones jurídicas en sus Cahiers pour une morale $e^{93}$. La violencia aparece sólo porque existe un Derecho respecto del cual se puede predicar que un acto se ha desviado o lo ha contrariado. La violencia en sí se constituye y emerge sólo en la posibilidad de estar fuera o contra la ley. No hay propiamente violencia en donde todo aparenta ser violencia como se supone por algunos que ocurriría en el "estado de naturaleza", por ejemplo. Al menos debe haber "ley natural" respecto de la cual la violencia puede referir su existencia; su aparición. La violencia requiere de la ley y del Derecho para hacer su aparición como enemigo que le conserva y define. Sin el peligro constante de que el propio Derecho se transforme en su ser Otro, que resulta ser la propia ley, no existe el peligro de que la violencia tenga un lugar. Precisamente porque el lugar de la violencia fuera de la ley, en realidad está en el interior mismo del Derecho, es la razón por la cual se necesitan mutuamente en su emersión. A su vez, el Derecho, sólo existe allí donde existe violencia que contener y diferenciar. Diferenciar como violencia legítima y como violencia ilegítima, o en otras palabras, como juridicidad coercible, por un lado, o antijuridicidad, por el otro.

En este punto resulta interesante la distinción que Walter Benjamin realiza entre Violencia fundadora, conservadora y divina, por una parte, y huelga general política y huelga general revolucionaria, por otra.

La violencia fundadora viene a instaurar al Derecho como acto inaugural. Es el acto de violencia de constitución del Derecho ${ }^{94}$, el acto en el que la violencia se escinde como violencia del Derecho y violencia contra Derecho, o en otras palabras, y aquí una interpretación nuestra,

93. ROMANO, Bruno: "Sartre: Los otros y el Derecho". En: Tognonato, Claudio et al.: Sartre contra Sartre. Ediciones del Signo, Serie Colección Nombre propio, Buenos Aires, pp. 33-46, 2001, p. 34.

94. Tal vez por lo mismo su cercanía con Carl Schmitt. 
el acto a través del cual no sólo se instaura un Derecho (o un ordenamiento jurídico en concreto), sino que a través de cuál se presentan violencia y Derecho por primera vez, como fenómenos aparentemente diferenciados. Se trata de una violencia de carácter mítica ${ }^{95}$, en oposición a una violencia divina ${ }^{96}$.

En un segundo momento fenomenológico la violencia se presenta como violencia conservadora ${ }^{97}$, ya no como fundacional del Derecho, (y de la violencia misma como escisión negativa, en nuestra lectura), sino que como conservación del propio Derecho, o más propiamente, del Estado de Derecho.

Por otro lado, y a propósito de la distinción previa, Benjamin cree que es posible diferenciar claramente entre dos fenómenos que muestran o presentan en toda su evidencia el carácter violento del Derecho y el tono de violencia de la propia violencia. En ese sentido distingue entre huelga general política y huelga general revolucionaria ${ }^{98}$, valiéndose en su eje central de las reflexiones elaboradas por Georges Sorel ${ }^{99}$.

¿De qué manera enlazar todo este entramando teórico y especulativo con el derecho a huelga? Creo que la relación es evidente. Ya en el capítulo anterior hemos develado una gran cantidad de inconvenientes teóricos y prácticos que se derivan de la configuración de la huelga como un derecho, y en particular, como un derecho

95. PÉREZ LÓPEZ, Carlos: "La idea de mito. Una zona equívoca entre Walter Benjamín y Georges Sorel”. En: Fenomenología, Firma y traducción. En torno a Jacques Derrida. VV.AA. Pólvora Editorial, Santiago de Chile, pp. 321-346, 2015, p. 325.

96. CAMPOS SALVATERRA, Valeria: "El gran criminal. Violencia, ley y soberanía”. En: Fenomenología, Firma y traducción. En torno a Jacques Derrida. V.AA. Santiago de Chile: Pólvora Editorial, pp. 371-405, 2015, p. 379.

97. BENJAMIN, Walter: ob. cit., p. 32.

98. Ibíd. P. 36.

99. SOREL, Georges: Reflexiones sobre la violencia. Trad. de Luis Alberto Ruiz. La Pléyade, Buenos Aires, 1973.

Facultad de Derecho y Ciencias Sociales - Universidad de Valparaíso - Chile 
fundamental. A fin de respetar la extensión de esta presentación no ahondaremos nuevamente en dichos inconvenientes, y los damos por enteramente reproducidos en esta parte. Pero nuevamente, ¿qué huelga (violenta o pacífica)?, ¿̇qué derecho para qué Derecho, y contra qué, o peor, en general, para qué?

En este punto, es posible afirmar que la consagración de la huelga como derecho, y como derecho fundamental consecutivamente, no es más que la apropiación histórica que el propio Derecho realiza de aquella violencia que en sus orígenes amenazaba con ser una violencia de nuevo tipo; una violencia incluso más que fundadora o instauradora; una violencia revolucionaria, en el sentido de que en sí misma su aparición era el momento de la negación del Estado de Derecho; la posibilidad de acabar de una vez por todas con el Derecho mismo, y trascender así la violencia conservadora del mismo, y por supuesto, y lo que es más difícil, la violencia fundacional. En ese sentido, una violencia de tales características, ejercida históricamente por los trabajadores es lo que podríamos llamar una violencia revolucionaria, tal como señala el profesor Carlos Pérez Soto ${ }^{100}$.

Una violencia revolucionaria que busca acabar con lo que Marcuse ha llamado "represión excedente"101. Una violencia sobrante que el Estado de Derecho en su afán conservador ha llevado al límite, permitiendo a algunos afirmar incluso que estado normal de la cuestión es el "estado de excepción"102.

Pero entonces, ¿̇qué sucede con el análisis de la relación entre violencia y el derecho a huelga? En primer lugar, la violencia y el derecho a huelga, tal como ocurre en general con el Derecho, encuentran una relación constitutiva e interdependencia de mayor grado. La huelga es violenta antes de la llegada del derecho, porque precisamente en tanto violencia, es uno de los momentos que posibilitan el reconocimiento y conservación del Derecho y lo jurídico. Pero en un segundo momento,

100. PÉREZ SOTO, Carlos: Marxismo Aquí y Ahora. Editorial Triángulo, Santiago de Chile, 2014, p. 100.

101. MARCUSE, Herbert: Eros y Civilización. Ed. Sarpe Madrid, 1983, p. 145.

102. AGAMBEN, Giorgio: Homo Sacer: El poder soberano y la nuda vida, I. Valencia, España: PRE-TEXTOS, 2006, p. 68.

Revista de Ciencias Sociales - Número 70 (2017) - Universidad de Valparáíso - ISSN 0716-7725-Valparaíso, Chile 
como derecho a huelga, y como derecho fundamental a huelga, ésta es intrínsecamente violencia en cuanto es uno de los lugares de lucha interna del Derecho en donde la violencia lucha por ser ella misma Derecho (en su faz conservadora). En cierto sentido, puede sostenerse que la huelga es como mínimo per se violenta pues su esencia, o al menos su centro de imputación que podrá ser puesto sometido al balancing test, o su contenido esencial cautelar prima facie, se constituye precisamente por la acción generalizada de perturbar al otro; por la noción de interferencia intersubjetiva. Como mínimo, el derecho a huelga supone la perturbación de los derechos del otro, aún antes de ser sometido a ponderación, siempre su ejercicio supone la interferencia de intereses jurídicamente protegidos de terceros. Una pretensión resistida que ni siquiera requiere un titular, pues su mera conceptualización instala dicha tensión intersubjetiva.

Pero añádase a lo anterior que, inmediatamente, la huelga es por sí violenta, porque en cuanto el Derecho hace suyo el derecho a huelga, y éste pasa a ser letra viva del lenguaje de los derechos, en cada ocasión que se cautele, se otorgue protección jurisdiccional o simplemente se le invoque como cobertura legal para determinadas actuaciones; en cada una de aquellas ocasiones, de ser confirmadas como coherentes con el principio de juridicidad, no existe una violencia exterior que someta a otro sujeto de derecho ilegítimamente, sino que es el propio Derecho, que en su ejercicio de la violencia en variante conservadora del Derecho someterá en particular a otro a través de un ejercicio de poder, no porque se encuentre cautelando un fin perseguido por la huelga, y que le trascienda (comunismo, anarquismo, derrocamiento de un gobierno, aumento de salarios, mejoras en la distribución de jornada, etc.) sino que más bien porque el Derecho mismo es quien ejerce dicha violencia en protección o conservación de sí; he ahí el carácter legítimo de la conducta analizada y que puede ser subsumida como huelga en ejercicio de un derecho fundamental. Valiéndonos de los términos utilizados por Iván Trujillo, he aquí su "estructura fenomenológica o tautología performativa" ${ }^{03}$, la del Derecho en su dinámica fundacional-conservadora.

103. TRUJILLO, Iván. "Complicidad, complicación y coimplicación. Políticas de la deconstrucción”. En: Fenomenología, Firma y traducción. En torno a Jacques

Derrida. VV.AA. Santiago de Chile: Pólvora Editorial pp. 301-320, 2015, p. 307.

Facultad de Derecho y Ciencias Sociales - Universidad de Valparaíso - Chile 
La huelga, o en general, la acción colectiva perturbadora de derechos de un empleador podrá ser considerada legítima y cubierta por el derecho fundamental a huelga, sólo si el Derecho mismo es quién no es puesto en la palestra. El derecho a huelga como derecho fundamental pierde necesariamente la posibilidad de ser portadora de una violencia de nuevo tipo, y sujeta su campo de acción legítima, precisamente, a lo legítimo, a lo propiamente jurídico, que no es sino la conservación del propio Derecho.

En palabras de Jacques Derrida, "La violencia no es exterior al orden del derecho. Amenaza al derecho en el interior del derecho. No consiste esencialmente en ejercer su poder o una fuerza bruta para obtener tal o cual resultado sino en amenazar o en destruir un orden de derecho dado, y precisamente, en este caso, el orden de derecho estatal que ha tenido que conceder ese derecho a la violencia, por ejemplo, el derecho a huelga" 104 .

En este sentido, tanto Evelyn Matthei, rostro político de la derecha chilena, como Bárbara Figueroa, presidenta de la Central Unitaria de Trabajadores y militante del Partido comunista se encuentran paradójicamente en lo correcto ${ }^{105}$. Es necesario discutir sobre el carácter eventualmente violento de la huelga, pero a su vez, es necesario también preocuparse el contenido de la misma, de entender qué se refiere con la huelga, y a lo menos, transparentar cuáles son los límites que el propio Estado de Derecho otorga a este concepto jurídico indeterminado. Por lo mismo la expresión usada en el proyecto de ley presidencial ${ }^{106}$ y que fue finalmente retirada no era para nada baladí, llama a poner atención en un espacio en donde la contradictoriedad del Derecho y su afán de auto conservación es más evidente que en otros lares.

104. DERRIDA, Jacques: Fuerza de ley. El "fundamento místico de la autoridad". Tecnos, Barcelona, 2008, p. 89.

105. A propósito de dos columnas publicadas en el diario La Tercera de Chile el día Sábado 12 de Septiembre de 2015, p. 10 : Evelyn Matthei. "Una Cláusula que resulta necesaria”. Y Bárbara Figueroa. "Este no es el problema central”.

106. Proyecto de ley presentado por el Gobierno de la Presidenta Michelle Bachelet el 29 de diciembre del año 2014. "La huelga es un derecho que debe ser ejercido colectiva y pacíficamente por los trabajadores” BACHELET (2014) p. 349.

Revista de Ciencias Sociales - Número 70 (2017) - Universidad de Valparáíso - ISSN 0716-7725-Valparaíso, Chile 
La posibilidad de otorgar un determinado carácter violento a la huelga como derecho fundamental está anclada a la violencia que el Derecho se permita institucionalizar y transformar en violencia conservadora, al cooptar su lenguaje por venir, para traducirlo al lenguaje de los derechos. Tal como señala un autor nacional: "para canalizar el conflicto es preciso institucionalizarlo, a saber, permitir su expresión dentro de un cierto contexto regulatorio"107. El consagrar a la huelga como un derecho fundamental facilita la institucionalización de la huelga como un momento más de la violencia del Derecho, y se pone a disposición de su violencia excedente ${ }^{108}$, y la administración de la diferencia a través de la tolerancia represiva. La huelga pasa a ocupar un lugar o función social, que como instancia de catarsis colectiva abre la posibilidad a la exteriorización del malestar subjetivo con expresiones igualmente contenidas y reprimidas, violentadas en la traducción de la violencia conservadora del Derecho.

\section{IV. ¿HAY OTRA HUELGA POSIBLE?}

Creo que precisamente el lenguaje de los derechos, y en particular de los derechos fundamentales, permiten llevar al límite la propia lógica jurídica iusfundamentalista, evidenciando sus contradicciones, e insuficiencias lógicas y prácticas. En este punto, prácticas efectivas de violencia, como la huelga, pueden presentar la opción de un nuevo tipo de violencia, que trascienda tanto a la violencia fundadora como a la conservadora, en la lectura benjaminiana del problema. En su momento, por su clara influencia judaica Benjamin refiere a la violencia divina como una violencia no condicionada; no atada a la violencia mítica. Desde un punto de vista radical, y que prescinda de un discurso teológico, la violencia revolucionaria (identificada en cierta medida con la huelga general proletaria) puede ser la promesa de un nuevo tipo de violencia, y la posibilidad de la deconstrucción de todo Derecho, para

\footnotetext{
107. GAMONAL CONTRERAS, Sergio: "El derecho a huelga en la constitución chilena”. Revista de derecho (Coquimbo), 20(1), 105-127, 2013.

108. PÉREZ SOTO, Carlos: ob.cit., p. 100.
}

Facultad de Derecho y Ciencias Sociales - Universidad de Valparaíso - Chile 
abrir efectivamente a la humanidad a un mundo nuevo, a un mundo Otro, hacia el por venir.

Jurídicamente, el análisis del carácter violento de la huelga se puede abordar claramente desde dos puntos de vista. El primero relacionado con la circunstancia ineludible de que por definición la huelga, y el ejercicio del derecho a huelga tendrá siempre un carácter violento, de manera constitutiva. El derecho a huelga se sostiene en la posibilidad de interferir a un tercero; no es que se invada la esfera de protección jurídica de un tercero en virtud de ser titular de un derecho, y que por lo mismo estaremos eventualmente ante lo que la doctrina neoconstitucionalista ha llamado "colisión de derechos", sino que aún antes, ies el derecho mismo el que contiene en su propia conceptualización la limitación de los derechos de otro! En ese sentido, cualquier perturbación será sin duda violenta para quien deba soportar la carga del ejercicio del derecho a huelga si se le estima un derecho fundamental.

Desde un segundo punto de vista, pero de manera inseparable a lo anterior conforme a lo que hemos expuesto, es preciso leer atentamente cuales serían los límites inmanentes al derecho de huelga, porque si en su constitución ya representa una manifestación de violencia, en su ejercicio resulta más evidente que cualquier intervención o perturbación porta un indicio de violencia. Por lo mismo, y aquí volvemos al vínculo con Benjamin, habrá que estar a lo que el propio Derecho establezca como violencia permitida del derecho a huelga, para conservar el monopolio de la fuerza. ¿Qué ocurre con quienes incurren en vías de hecho respecto del empleador o de sus propios compañeros de trabajo, estén éstos sindicalizados o no? Sumo cuidado en este punto, pues el entender cubiertas estas acciones por el Derecho (legitimadas en otras palabras), implica para el Derecho a fin de contener la violencia Otra, hacer suya un excedente de violencia que desestabiliza su propio orden.

Una cuestión diversa, y que no hemos tratado en este estudio refiere a las sanciones, o consecuencias jurídicas de incurrir los huelguistas en acciones que el propio Derecho considere como violentas, y por tanto, ilegítimas. ¿Cuáles son las sanciones aplicables? De suma relevancia este punto pues habrá que analizar cuáles son los efectos de considerar que la relación de trabajo se encuentra suspendida durante

Revista de Ciencias Sociales - Número 70 (2017) - Universidad de Valparáíso - ISSN 0716-7725-Valparaíso, Chile 
la duración de la huelga, cuál es el rol de la judicatura con competencia laboral y/ eventualmente la penal.

La única huelga posible en el marco jurídico del Estado de Derecho es la huelga no violenta (o pacífica), pero a su vez, dicha huelga supone una violencia permitida por el propio Derecho, como manifestación de su conservación. Ahora, chasta qué punto puede soportar hacer suya la violencia propia de la huelga, y el enfrentamiento intersubjetivo? Esperamos en otra ocasión abordar también este problema en detalle.

\section{CONCLUSIONES}

La huelga se presenta históricamente, en primer lugar, como un fenómeno colectivo previo a la codificación y juridización especializada de las relaciones de trabajo. Vinculada al movimiento obrero, por algunos podrá asociarse con la persecución de los medios básicos de subsistencia, por otros, en cambio, con un medio de fuerza carácter revolucionario. El Derecho cooptó a la huelga como huelga política (revolucionaria), dejando abierta sólo la posibilidad a la huelga jurídica o legítima (general política). ¿Qué se dice cuando se dice que existe un derecho fundamental a huelga?, se dice lo que el Derecho quiere que se pueda decir; bajo las leyes de su predicación. En esa dirección, tiene sentido la despreocupación sobre el análisis del carácter violento de la huelga, y sería lógico predicar solo la preocupación por su protección y consagración judicial en un sentido amplio; sólo ahí podemos afirmar "no importa si la huelga es violenta o no; lo que importa es realmente su protección”. Resulta obvio, porque incluso implícitamente se reconoce que el contenido mismo del derecho está imbuido de violencia. El asunto será determinar cuál es la violencia que lo constituye, y desde esa perspectiva, la huelga no puede sino ser violenta.

La huelga es siempre violenta, pero ahora, como derecho fundamental, no es una violencia completamente Otra del derecho, sino que es en la huelga misma que el Derecho actúa violentamente, al menos en dos direcciones: limitando las posibilidades políticas de la huelga como horizonte emancipador, y en ese sentido se vuelve contra un sujeto histórico que trasciende al titular del derecho a huelga; el

Facultad de Derecho y Ciencias Sociales - Universidad de Valparaíso - Chile 
sujeto revolucionario. Pero por otro lado, el derecho a huelga es también la violencia del Derecho contra sí mismo. Contra otros titulares de derechos subjetivos, como lo son los empleadores detentadores del derecho de propiedad. Pero no sólo respecto de aquellos, sino que dependiendo de la definición que tengamos de la huelga en una de sus varias modalidades, la huelga se vuelve violenta también contra otros titulares que no son empleadores, como en el caso de los servicios esenciales, o incluso, contra otros trabajadores que en una circunstancia concreta pueden no estar haciendo uso legítimo del derecho a huelga, o derechamente contra el Estado (de Derecho) mismo, como cuando se altera el Orden Público y la Seguridad Nacional. Violencia contra otros trabajadores en cuanto vulneran su libertad de trabajo, eventualmente su integridad física, su derecho a salud o su integridad psíquica. ¿Por qué se hace esto? Por qué el Derecho deja tal apertura a la violencia contra sí mismo en su propio seno, siendo a menudo evidentemente inconsistente? Por una razón simple. Se pretende sublimar la pulsión latente. Se pretende sublimar la pulsión que podría tener orientación propiamente revolucionaria, encontrando vías legítimas y controlables de violencia que permitan conservar el Derecho. La huelga como derecho fundamental, el discurso de los derechos fundamentales en general como un discurso de violencia legitimada, no es más que el discurso de la violencia del Derecho luchando por su propia conservación, Es el Derecho presentado en su desesperación por seguir siendo, habrá que ver hasta dónde da el elástico.

\section{BIBLIOGRAFIA}

AGAMBEN, Giorgio: Homo Sacer: El poder soberano y la nuda vida, I. Valencia, España: PRE-TEXTOS, 2006.

ALDUNATE LIZANA, Eduardo: "Aproximación conceptual y crítica al neoconstitucionalismo". Revista de derecho (Valdivia), 23(1), 79-102, 2010.

ALEXY, Robert: Teoría de los derechos fundamentales, trad. de Ernesto Garzón Valdés. Centro de Estudios Políticos y Constitucionales, Madrid, 2001.

ANGELL, Alan. Partidos Políticos y movimiento obrero en Chile. Ediciones ERA, México, 1974.

Revista de Ciencias Sociales - Número 70 (2017) - Universidad de Valparáíso - ISSN 0716-7725-Valparaíso, Chile 
BACHELET JERIA, Michelle (2014): “Mensaje N 1055/362” Disponible en: https://www.camara.cl/pley/pley_detalle.aspx? prmID $=10248 \&$ prmBoletin $=9835-13$

BAYLOS GRAU, Antonio Pedro. "Estado democrático de Derecho y amplio reconocimiento del derecho de huelga". Derecho laboral:

Revista de doctrina, jurisprudencia e informaciones sociales, $\mathrm{N}^{\circ} 242,2011$.

BENJAMIN, Walter: Para una crítica de la violencia y otros ensayos, Iluminaciones IV, Introducción y selección de Eduardo Subirats.

Traducción de Roberto Blatt, Madrid, Taurus, 1991.

BENJAMIN, Walter: Para una crítica de la violencia y otros ensayos, Iluminaciones IV, Introducción y selección de Eduardo Subirats.

Traducción de Roberto Blatt, Taurus, Madrid, 1991.

BUTLER, Judith. ¿A quién le pertenece Kafka? Palinodia, Santiago de Chile, 2014.

CAAMAÑO ROJO, Eduardo: "La eficacia de los Derechos Fundamentales en las relaciones laborales y su reconocimiento por

la Dirección del Trabajo”. En: Revista de Derecho de la Pontificia Universidad Católica de Valparaíso. Vol. XXVII, Semestre I, 2006.

CAMPOS SALVATERRA, Valeria: "El gran criminal. Violencia, ley y soberanía”. En: Fenomenología, Firma y traducción. En torno a

Jacques Derrida. VV.AA. Santiago de Chile: Pólvora Editorial, pp. 371405, 2015.

COLOMBO CAMPBELL, Juan: La Jurisdicción en el Derecho Chileno. Editorial Jurídica de Chile Santiago de Chile, 1991.

CRUZ PARCERO, Juan Antonio: El lenguaje de los derechos. Ensayo para una teoría estructural de los derechos, Trotta, 2007.

D'AURIA, Aníbal: "Introducción al ideario anarquista". En: AA.VV. El anarquismo frente al derecho: Lecturas sobre Propiedad, Familia,

Estado y Justicia. Aníbal D’Auria. [et.al], Libros de Anarres, Buenos Aires, 2007.

DERRIDA, Jacques: Fuerza de ley. El "fundamento místico de la autoridad". Tecnos, Barcelona, 2008.

DERRIDA, Jacques: Fuerza de ley. El "fundamento místico de la autoridad". Tecnos, Barcelona, 2008.

DERRIDA, Jaques: La diferencia. Edición electrónica de www. philosophia.cl / Escuela de Filosofía Universidad ARCIS.

Facultad de Derecho y Ciencias Sociales - Universidad de Valparaíso - Chile 
Recuperado de: http://www.uruguaypiensa.org.uy/imgnoticias/590.pdf 1968.

DEVÉS, Eduardo y DÍAZ, Carlos: El pensamiento socialista en Chile (Antología 1893-1933). Ediciones Documentas, Santiago de Chile, 1987.

ESTRADA VÉLEZ, Sergio: "La Ponderación o la débil frontera entre la arbitrariedad y el uso legítimo de la discrecionalidad". En: Revista Vniversitas. Bogotá (Colombia) N 121, julio-diciembre, pp. 77 112, 2010.

GAETE BERRÍOS, Alfredo. Manual de derecho del trabajo. Editorial Jurídica de Chile, Santiago de Chile, 1949.

GAMONAL CONTRERAS, Sergio. "El derecho a huelga en la constitución chilena". En: Revista de derecho (Coquimbo), 20(1), 105127, 2013.

GAMONAL CONTRERAS, Sergio: "El derecho a huelga en la consti2013. tución chilena". Revista de derecho (Coquimbo), 20(1), 105-127,

GAMONAL CONTRERAS, Sergio: Ciudadanía en la empresa o los derechos fundamentales inespecíficos. Fundación de Cultura

Universitaria, Editorial Jurídica, Uruguay, 2004.

GAMONAL CONTRERAS, Sergio: Derecho Colectivo del Trabajo. 2a edición. Abeledo Perrot, Santiago de Chile, 2011.

GARCÍA AMADO, Juan Antonio: "El juicio de ponderación y sus partes. Una crítica”: En: Alexy, Robert (coord.), Derechos sociales

y ponderación, Fundación Coloquio Europeo, Madrid, 2007.

GARCÍA, José Francisco y VERDUGO, Sergio. Activismo judicial en Chile ¿Hacia el gobierno de los jueces? Ediciones Libertad y

Desarrollo, Santiago de Chile, 2013.

GLENDON, Mary Ann: "El lenguaje de los derechos". Estudios Públicos, $\mathrm{N}^{\circ}$ 70, Santiago de Chile, 1998.

GREZ TOSO, Sergio: Los anarquistas y el movimiento obrero. La alborada de "la Idea" en Chile: 1893-1915. Santiago, LOM Edi-

ciones, 2007.

HARNECKER, Marta: Los conceptos elementales del materialismo histórico. Siglo XXI 24 edición, Madrid, 1974.

HENRY MERRYMAN, John: La tradición jurídica Romano Canónica. Fondo de Cultura Económica, $2^{\circ}$ reimpresión, México, 1980.

Revista de Ciencias Sociales - Número 70 (2017) - Universidad de Valparaíso - ISSN 0716-7725-Valparáiso, Chile 
HOBBES, Thomas: Leviatán, o La materia, forma y poder de una república eclesiástica y civil. Editorial Sarpe. Madrid, 1984.

JAKOBS, Günther y CANCIO MELIÁ, Manuel: Derecho penal del enemigo. Civitas, Madrid, 2003.

KANT, Immanuel: Principios metafísicos del Derecho, trad. de Gonzalo Lizárraga, Librería de Victoriano Suárez, Madrid,1873.

KELSEN, Hans. Teoría pura del derecho. Porrúa, México, 1998.

KENNEDY, Duncan: Izquierda y derecho. Ensayos de teoría jurídica crítica. Buenos Aires: Editorial Siglo XXI, 2010.

KENNEDY, Duncan: Izquierda y derecho. Ensayos de teoría jurídica crítica. Editorial Siglo XXI, Buenos Aires, 2010.

MARCUSE, Herbert: Eros y Civilización. Ed. Sarpe Madrid, 1983.

MARZI, Daniela: "¿Quién le teme a los derechos fundamentales? Sobre el procedimiento de tutela de la Reforma Laboral”. En: Anuario de Derechos Humanos, $\mathrm{N}^{\circ}$ 6, 2010.

MILLAS, Jorge: Filosofía del derecho. Comentarios, notas y edición de Juan O. Cofré. Santiago, Chile, Ediciones Universidad Diego Portales, 2012.

MUÑOZ CORTÉS, Víctor: Sin Diosni patrones. Mar y Tierra ediciones, Santiago de Chile, 2013.

NINO, Carlos Santiago: Introducción al análisis del derecho. Ariel, Barcelona, 1997.

NOGUEIRA ALCALÁ, Humberto: "El bloque constitucional de derechos en Chile, el parámetro de control y consideraciones comparativas con Colombia y México: doctrina y jurisprudencia”. En: Estudios constitucionales, 13(2), 301-350, 2015.

NÚÑEZ POBLETE, Manuel A.: "El neoconstitucionalismo y el recurso a los valores en la jurisprudencia del Tribunal Constitucional chileno". Revista de derecho (Valparaíso), (34), 523-541, 2010.

OIT: La libertad sindical - Recopilación de decisiones y principios del Comité de Libertad Sindical del Consejo de Administración de la OIT. Quinta edición (revisada), 2006.

PÉREZ LÓPEZ, Carlos: "La idea de mito. Una zona equívoca entre Walter Benjamín y Georges Sorel”. En: Fenomenología, Firma y traducción. En torno a Jacques Derrida. VV.AA. Pólvora Editorial, Santiago de Chile, pp. 321-346, 2015.

Facultad de Derecho y Ciencias Sociales - Universidad de Valparaíso - Chile 
PÉREZ SOTO, Carlos: Marxismo Aquí y Ahora. Editorial Triángulo, Santiago de Chile, 2014.

RICCEUR, Paul. Lo Justo. Editorial Jurídica de Chile, Santiago de Chile, 1997.

ROMANO, Bruno: "Sartre: Los otros y el Derecho". En: Tognonato, Claudio et al.: Sartre contra Sartre. Ediciones del Signo, Serie Colección Nombre propio, Buenos Aires, pp. 33-46, 2001.

ROUSSEAU, Jean Jacques: El contrato social. Ed. Centro gráfico, Santiago de Chile, 2005.

ROXIN, Claus: El concepto de bien jurídico como instrumento de crítica legislativa sometido a examen. En: Revista electrónica de ciencia penal y criminología, No 15, 2013, Rescatado de: http://criminet.ugr.es/ recpc/15/recpc15-01.pdf

RUAY SÁEZ, Francisco: "Una crítica al juicio de ponderación de Alexy a propósito del procedimiento de Tutela Laboral". En: Revista de Derechos Fundamentales, Universidad de Viña del Mar, No 12, 2014. RUIZ GUTIÉRREZ, Adriana María: "Walter Benjamin: una crítica a la violencia del derecho". Revista Estudio de Derecho, Universidad de Antioquia. Vol. 69, No 153, 2012, Rescatada en: http:// aprendeenlinea.udea.edu.co/revistas/index.php/red/article/view/14141/ 12501

SALAZAR, Gabriel: "Proyecto histórico social y discurso político nacional. Chile, siglo XIX”. En: Loyola, Manuel y Grez, Sergio (compiladores). Los proyectos nacionales en el pensamiento político y social chileno del siglo XIX. Ediciones UCSH, colección Monografías y Textos, Santiago, 2002.

SALAZAR, Gabriel: Labradores, peones y proletarios (Siglo XIX). Ediciones SUR, Santiago de Chile, 1989.

SERNA, Pedro y TOLLER, Fernando: La interpretación constitucional de los derechos fundamentales. Una alternativa a los conflictos de los derechos, La Ley, Buenos Aires, 2000.

SOREL, Georges: Reflexiones sobre la violencia. Trad. de Luis Alberto Ruiz. La Pléyade, Buenos Aires, 1973.

SQUELLA NARDUCCI, Agustín: Introducción al Derecho. Editorial Jurídica de Chile, Santiago de Chile, 2000.

TANNENBAUM, Frank: Filosofía del trabajo. Traducción de Magdalena Santa Cruz. Editorial del Pacífico, Santiago de Chile, 1955. 
TAPIA, Francisco: Sindicato en el derecho chileno del trabajo. Ed. LexisNexis, Santiago, 2005.

TOLEDO CORSI, César. Tutela de la Libertad Sindical. Abeledo Perrot, Legalpublishing, Santiago de Chile, 2013.

TRUJILLO, Iván. "Complicidad, complicación y coimplicación. Políticas de la deconstrucción". En: Fenomenología, Firma y traducción. En torno a Jacques Derrida. VV.AA. Santiago de Chile: Pólvora Editorial pp. 301-320, 2015.

UGARTE CATALDO, José Luis y CAAMAÑO ROJO, Eduardo. Negociación colectiva y libertad sindical: un enfoque crítico. Legal

Publishing, Santiago de Chile, 2008.

UGARTE CATALDO, José Luis. "La subordinación jurídica y los desafíos del nuevo mundo del trabajo". Gaceta Laboral, 11(1), 2005.

UGARTE CATALDO, José Luis: "La constitucionalización del derecho del trabajo: la tutela de derechos fundamentales". En: Revista Latinoamericana de Derecho Social, No 7, julio-diciembre de 2008, 2008.

UGARTE CATALDO, José Luis: "Los derechos en su nueva hora: la teoría externa de los derechos fundamentales". Revista de derecho (Coquimbo), 18(2), 361-373, 2011.

UGARTE CATALDO, José Luis: "Los derechos en su nueva hora: la teoría externa de los derechos fundamentales". Revista de derecho (Coquimbo), 18(2), 361-373, 2011.

UGARTE CATALDO, José Luis: "Los Derechos Fundamentales del Trabajador: el nuevo procedimiento de tutela laboral”, Colección Ensayos Jurídicos, Universidad Alberto Hurtado, No 2, 2006.

Universidad Diego Portales: Informe anual sobre derechos humanos en Chile. Ediciones UDP, Santiago de Chile, 2014.

VERDUGO, Mario; PFEFFER, Emilio y NOGUEIRA, Humberto: Derecho Constitucional. Tomo I, 2a edición actualizada. Editorial Jurídica de Chile, Santiago de Chile, 1999.

VERGARA BLANCO, Alejandro: "Delimitar y distinguir: teoría del derecho, filosofía del derecho y doctrina jurídica". En: Revista de derecho (Valparaíso), N ${ }^{\mathrm{a}}$ 44, 623-660, 2015.

Facultad de Derecho y Ciencias Sociales - Universidad de Valparaíso - Chile 